\title{
TAIMI HAENSEL
}

OS DESAFIOS DA REGULAÇÃO DO HIGH FREQUENCY TRADING NO BRASIL - UMA ABORDAGEM PRUDENCIAL À LUZ DAS TRANSFORMAÇÕES OPERADAS PELA INOVAÇÃO TECNOLÓGICA NO MERCADO DE VALORES MOBILIÁRIOS

Tese de Doutorado

Orientador: Prof. Dr. Francisco Satiro de Souza Junior

UNIVERSIDADE DE SÃO PAULO

FACULDADE DE DIREITO

São Paulo-SP

2019 


\title{
TAIMI HAENSEL
}

\section{OS DESAFIOS DA REGULAÇÃO DO HIGH FREQUENCY TRADING NO BRASIL - UMA ABORDAGEM PRUDENCIAL À LUZ DAS TRANSFORMAÇÕES OPERADAS PELA INOVAÇÃO TECNOLÓGICA NO MERCADO DE VALORES MOBILIÁRIOS}

\begin{abstract}
Tese apresentada à Banca Examinadora do Programa de Pós-Graduação em Direito da Faculdade de Direito da Universidade de São Paulo, na área de concentração de Direito Comercial, como exigência parcial à obtenção do título de Doutora em Direito, sob a orientação do Prof. Dr. Francisco Satiro de Souza Junior.
\end{abstract}

UNIVERSIDADE DE SÃO PAULO

FACULDADE DE DIREITO

São Paulo-SP

2019 
Ficha Catalográfica

\section{Faculdade de Direito da Universidade de São Paulo}

Haensel, Taimi

Os Desafios da Regulação do High Frequency Trading no Brasil - Uma abordagem prudencial à luz das transformações operadas pela inovação tecnológica no mercado de valores mobiliários / Taimi Haensel. -- São Paulo: USP / Faculdade de Direito, 2019.

240f.

Orientador: Prof. Dr. Francisco Satiro de Souza Junior.

Tese (Doutorado), Universidade de São Paulo, USP, Programa de PósGraduação em Direito - área de concentração, Direito Comercial, 2019.

1. Direito do Mercado de Valores Mobiliários. 2. Regulação. 3. Bolsa de Valores. 4. Negociação em Alta Frequência. 5. Inovação Tecnológica. I. Souza Junior, Francisco Satiro de. II. Título.

CDU 


\section{FOLHA DE APROVAÇÃO}

Nome: Taimi Haensel

Título: Os Desafios da Regulação do High Frequency Trading no Brasil - Uma abordagem prudencial à luz das transformações operadas pela inovação tecnológica no mercado de valores mobiliários

Natureza: Tese de Doutorado

Instituição: Faculdade de Direito da Universidade de São Paulo

Orientador: Prof. Dr. Francisco Satiro de Souza Junior

Área de Concentração: Direito Comercial

Data da Banca:

Banca Examinadora

Prof. Dr. Francisco Satiro de Souza Junior (Orientador) 
Para Lucas e nossa família, como sempre. 


\section{AGRADECIMENTOS}

Muitas foram as pessoas que fizeram parte da minha vida nos últimos anos, permitindo a conclusão desta tese. Ela não seria possível sem vocês.

Agradeço ao meu orientador, Professor Dr. Francisco Satiro, pela orientação presente, sincera, dedicada e exigente. Não há como agradecer suficientemente.

Agradeço a minha banca de qualificação, Professores Ilene Patrícia Najjarian e Marcos Galileu Lorena Dutra pela análise profunda e detalhada que me permitiu melhor direcionar este trabalho. Agradeço à Professora Sheila Christina Neder Cerezetti pelo apoio em momento crucial.

Agradeço aos meus amigos queridos. Adriana Cristina Dullius foi força e incentivo quando tudo me faltou. Você acreditou, e isso bastou para mim. Maria Augusta da Matta Rivitti ordenou que eu fizesse a seleção do doutorado. Serei eternamente grata. Ivy Casa me ajudou a rir, quando rir era improvável, mas necessário. O grupo de amigos Habeas Data, desde a graduação, é minha fonte de amor incondicional. A Família Yokomizo foi a melhor família que uma doutoranda poderia ter.

A fase do doutorado trouxe de presente amigos novos. Agradeço a Irineia Maria Senise, por manter viva a minha fé e esperança. Agradeço a Alessandra Domingues, por dar o exemplo e lutar junto. Agradeço a Marli Moraes pela revisão minuciosa.

Amigos foram chamados a "trocar uma ideia por cinco minutos" nos horários mais inconvenientes. Agradeço a Valdir Carlos Pereira Filho, André Demarco, Luis Felipe Calabró e Isac Costa pela atenção.

Agradeço aos colegas do Centro de Estudos dos Mercados Financeiro e de Capitais - CEM por ampliar meu olhar sobre o tema que nos apaixona. Rafaella Flores Lellis, Marco Aurélio Antongiovanni, Lucas Toccheton Pinsdorf, Kevin Eiji Iwashita e Pedro Pinho foram meus companheiros neste novo caminho.

Ana Maria Rodrigues e Maria Florentino Rodrigues não deixaram faltar nem comida, nem café, nem broncas.

Agradeço a Alina, moça valente e encantadora, que me ajudou nesta pesquisa como ninguém. Fez comigo a seleção de doutorado. Subiu comigo as escadas até a biblioteca do quarto andar carregada de livros. Frequentou cinco disciplinas em um mesmo semestre antes mesmo de nascer. Certamente seus desenhos coloridos ("para o seu trabalhinho, mamãe") foram a melhor motivação para a conclusão deste trabalho.

Agradeço, principalmente, a Lucas por enfrentar comigo a tempestade e, assim, dividir a tarefa de ensinar Alina como se veleja a vida. 
HAENSEL, Taimi. Os Desafios da Regulação do High Frequency Trading no Brasil Uma abordagem prudencial à luz das transformações operadas pela inovação tecnológica no mercado de valores mobiliários. 2019. 240f. Tese (Doutorado). Faculdade de Direito da Universidade de São Paulo, São Paulo, 2019.

\section{RESUMO}

O presente estudo examina as negociações em alta frequência (o high frequency trading ou "HFT") em mercado de bolsa de valores mobiliários como um produto da inovação tecnológica. O HFT, que consiste em técnica de negociação recente, resultou em diversas transformações no mercado em questão. É, também, apontado como fonte de diversos problemas e riscos. A origem tecnológica da ferramenta precisa ser compreendida com o escopo de prover um tratamento adequado ao tema pelo direito do mercado de valores mobiliários. De forma específica, o enfoque deste estudo recai sobre a construção de um regime prudencial que proteja a integridade do mercado de bolsa. Sob esta perspectiva, analisou-se o HFT em função de quatro perfis da figura que evidenciam a sua essência como tecnologia da Era da Informação (o HFT-algoritmo, o HFT-sujeito, o HFT-estratégia e o HFT-ferramenta). A substância informacional, virtual, digital, que trafega em redes, dentre outros atributos identificados, demanda que o objeto em exame seja analisado em bases diversas do que aquelas empregadas no paradigma nas negociações tradicionais. Demonstradas as características do HFT como inovação tecnológica, apresenta-se a sua inserção na estrutura das operações do mercado de bolsa nacional e as repercussões disto para a bolsa, intermediários e investidores. Na sequência, o arcabouço regulatório em vigor é avaliado, de forma a refletir sobre seu alcance em termos prudenciais e do objetivo da integridade do mercado em confronto com os desafios que o HFT impõe. Por fim, propõem-se medidas que endereçam questões em que o HFT ainda carece de tratamento apropriado pelo Direito, reclamando que se utilizem tanto formas típicas de regulação quanto abordagens inovadoras para dar conta da perspectiva tecnológica da ferramenta.

Palavras-chave: Direito do Mercado de Valores Mobiliários - Regulação - Bolsa de Valores - Negociação em Alta Frequência - Inovação Tecnológica. 
HAENSEL, Taimi. The Challenges of Regulating High Frequency Trading in Brazil - A prudential approach in light of changes brought by technology innovation in the securities market. 2019. 240p. PhD Thesis, Faculty of Law, University of São Paulo, São Paulo, 2019.

\begin{abstract}
This study examines high frequency trading (or HFT) in securities markets as a product of technological innovation. HFT is a recent trading technique that has given rise to several transformations in the market. It is also pointed as source of several problems and risks. Its technological background must be understood in order to provide an adequate treatment to the subject by securities law. Specifically, this study is concerned with the construction of a prudential regime in light of market integrity. With this in mind, four profiles of the HFT (HFT-algorithm, HFT-subject, HFT-strategy and HFT-tool) which evidence its essence as an Age of Information technology are examined. The informational, virtual, digital substance that is transmitted through networks, among other attributes, require that the object under examination be analyzed in different grounds in comparison to those employed for analyzing traditional trading. Once the characteristic of HFT as a technological innovation have been presented, its inclusion in the structure of Brazilian securities markets trading and its repercussions to the exchange, intermediary institutions and investors are ascertained. The present regulatory regime is evaluated, in order to reflect on its reach in terms of prudential measures and of market integrity, in contrast to the challenges that HFT poses. Lastly, measures to address matters regarding HFT that still require an adequate legal approach are suggested, requiring that both typical regulation and innovative approaches are implemented so as to properly address the technological perspective of the tool.
\end{abstract}

Keywords: Securities Law - Regulation - Securities Markets - High Frequency Trading Technological Innovation. 
HAENSEL, Taimi. Les Défis de la Réglementation des Transactions à Haute Fréquence au Brésil - Une approche prudentielle à la lumière des transformations apportées par l'innovation technologique sur le marché des valeurs mobilières. 2019. 240p. Thèse (Doctorat). Faculté de Droit de l’Université de São Paulo, São Paulo, 2019.

\section{RESUMÉ}

La présente thèse fait une étude des transactions à haute fréquence ("THF") ou "trading haute fréquence" - "THF" (de l'anglais high frequency trading - HFT") sur le marché boursier, en tant que produit de l'innovation technologique. Le THF, qui consiste dans une technique récente de négociation, a entraîné plusieurs transformations sur le marché en question. Il est également vu comme source de plusieurs problèmes et de risques. L'origine technologique de cet outil doit être entendue dans le but de fournir un traitement convenable au droit du marché des valeurs mobilières. La thèse porte donc en particulier sur la mise en place d'un régime prudentiel protégeant l'intégrité du marché boursier. Dans cette perspective, les THF ont été analysés selon quatre profils, qui illustrent son essence en tant que technologie de l'ère de l'information (THF-algorithme, THF-sujet, THFstratégie et THF-outil). Le contenu informatif, virtuel et numérique qui circule dans les réseaux, entre d'autres attributs identifiés, exige que l'objet en question soit analysé sur des bases différentes de celles utilisées dans le paradigme des négociations traditionnelles. Démontrant les caractéristiques des THF, en tant qu'innovation technologique, on présente sont insertion dans la structure des opérations du marché boursier national et ses répercussions sur la bourse, les intermédiaires et les investisseurs. Par la suite, le cadre réglementaire en vigueur est évalué afin de réfléchir à sa portée prudentielle et à l'objectif d'intégrité du marché face aux défis que les THF imposent. Finalément, des mesures sont proposées pour traiter les problèmes pour lesquels les THF n'ont toujours pas reçu le traitement juridique approprié, appelant à la fois à des formes de réglementation standards et à des approches novatrices pour prendre en compte la perspective technologique de l'outil.

Mots-clefs: Droit du Marché des Valeurs Mobilières - Régulation - Bourse - Transactions de Haute Fréquence - Innovation Technologique. 


\section{SUMÁRIO}

INTRODUÇ̃̃O

1 PANORAMA DO HFT NO MERCADO DE VALORES MOBILIÁRIOS ........................23

1.1 Um novo mercado de bolsa para negócios tradicionais...................................................................23

1.2 O HFT - um novo modo de operar em um novo mercado de bolsa .................................................... 32

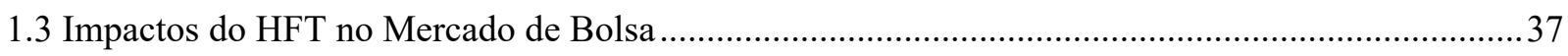

1.4 Algumas tendências no tratamento de problemas gerados pelo HFT …….........................................59

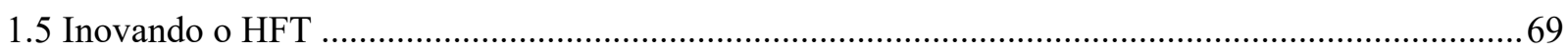

2 O HFT COMO INOVAÇÃO TECNOLÓGICA: ALGUNS PERFIS DA FIGURA...........77

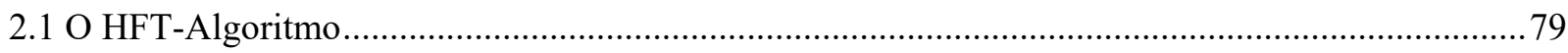

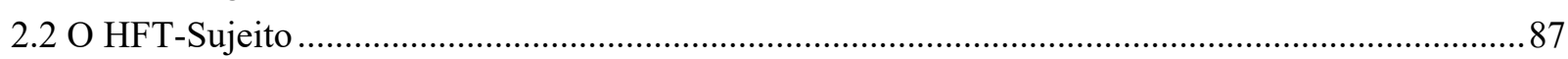

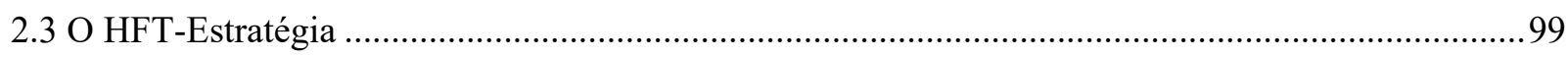

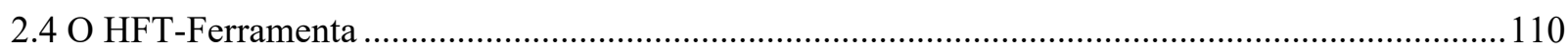

3 A ESTRUTURA TECNOLÓGICA DAS NEGOCIAÇÕES COM HFT NO BRASIL ... 119

3.1 A microestrutura do mercado de bolsa no Brasil: instituições e relações .........................................122

3.2 A infraestrutura das negociações com o HFT na bolsa brasileira................................................. 139

4 O ARCABOUÇO REGULATÓRIO PRUDENCIAL DO HFT EM VIGOR.................... 157

4.1 Normatização elaborada pela Comissão de Valores Mobiliários ...................................................... 159

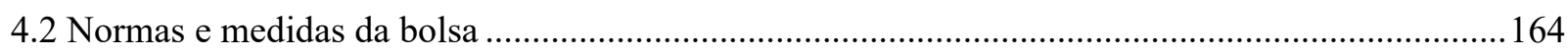

5 REGULAÇÃO PRUDENCIAL DO HFT: ALGUMAS REFLEXÕES FACE ÀS TRANSFORMAÇÕES DO MERCADO DE VALORES MOBILIÁRIOS EM FUNÇÃO DA INOVAÇÃO TECNOLÓGICA ……............................................................... 189

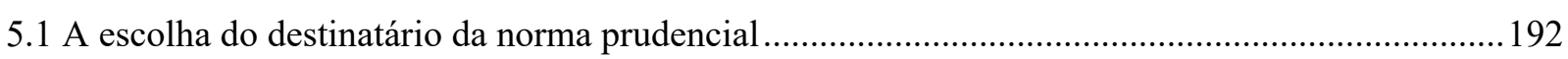

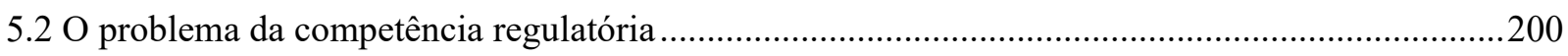

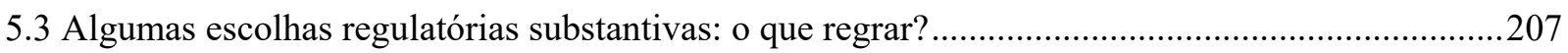

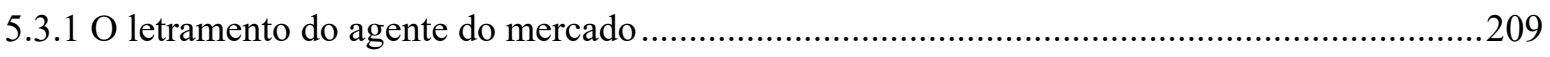

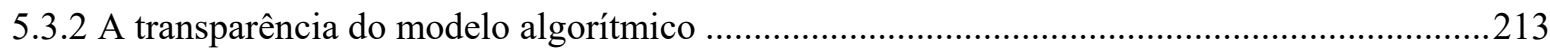

5.3.3 O alcance de "code is law" na regulação prudencial do HFT ................................................215

CONCLUSÃO

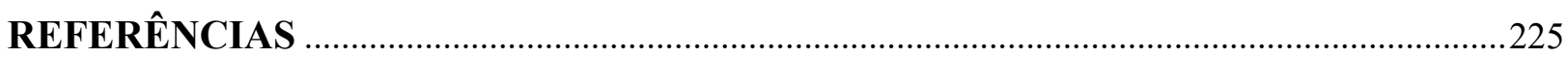




\section{INTRODUÇÃO}

A inovação tecnológica atingiu a sociedade como um todo nas últimas décadas. ${ }^{1} \mathrm{Na}$ seara do mercado de valores mobiliários, não foi diferente. ${ }^{2}$ Há um novo modo de negociar em bolsa, ${ }^{3}$ valendo-se de algoritmos de computador, rapidez e baixa latência: o high frequency trading ("HFT"). ${ }^{4}$

O HFT é inovação que surgiu no mercado de valores mobiliários, especificamente

${ }^{1}$ Tome-se alguns exemplos em campos bastante distintos para ilustrar isso em relação ao Brasil:

(i) No campo da saúde, vide o projeto 'Labdaps' da Faculdade de Saúde Pública da USP: "No Labdaps, como é conhecido o Laboratório de Big Data e Análise Preditiva da universidade, contam que usam essa base de dados para criar programas de inteligência artificial que, num futuro próximo, possam facilitar o diagnóstico de doenças, como dengue, zika ou chikungunya. Ou indicar o risco de um idoso desenvolver doenças que ameacem sua vida num prazo de 15 anos. 'Acreditava-se que as maiores transformações na medicina iriam ocorrer com o uso de robôs nos corredores ou centros cirúrgicos', afirma Chiavegatto. 'O grande avanço, porém, são os sistemas que reconhecem padrões em enfermidades e oferecem aos médicos elementos que o ajudem na tomada de decisão." NOBESCHI, Alexandre. Saúde: como a inteligência artificial pode ajudar nos diagnósticos: empresas apostam na inteligência artificial para ajudar nos diagnósticos. O vazamento de dados médicos privados é o efeito colateral mais temido pelos pacientes. Época, 26 dez. 2016. Disponível em: $\quad<$ https://epoca.globo.com/saude/noticia/2016/12/saude-como-inteligencia-artificial-pode-ajudar-nosdiagnosticos.html>. Acesso em: 17 dez. 2018.

(ii) No campo da proteção à soberania nacional, pesquisas tem buscado aprimorar a aplicação dos VANTs, os Veículos Aéreos Não Tripulados, que "são aeronaves projetadas para operar sem piloto a bordo.” Um dos aprimoramentos que se tem investigado é a maior autonomia dos VANTs, "reduzindo a dependência desses veículos de operadores remotos" mediante utilização de redes neurais artificiais, que "são sistemas de processamento de informações, inspirados na rede neural cerebral, usados com sucesso em diversas aplicações que envolvem o processamento de imagens." SILVEIRA, G. P.; SHIGUEMORI, E. H.; GOMES, V. C. F. Uso de Rede Neural Artificial para a Classificação de Vias Terrestres em Imagens Obtidas por VANTs. Revista Projetos de Engenharia, n. 2, p. 133-138, set. 2017. Disponível em: <revista.aeita.com.br/wpcontent/uploads/2017/.../Anais_VI_SCTI_2017-133-138.pdf >. Acesso em: 01 set. 2018.

(iii) No campo jurídico, sistemas de inteligência artificial já são comercializados no país, com capacidade para ler milhares de decisões judiciais e mesmo minutar documentos mais básicos. ALVAREZ, Luciana. Robôs podem ler processos e até escrever petições. Estadão, 14 ago. 2018. Disponível em: $<$ https://educacao.estadao.com.br/noticias/geral,robos-podem-ler-processos-e-ate-escreverpeticoes, 70002449375>. Acesso em: 01 dez. 2018.

2"Nowhere has disruptive technology had a more profound impact than in financial services - and yet nowhere do academics and policymakers lack a coherent theory of the phenomenon more, much less a coherent set of regulatory prescriptions." BRUMMER, Chris. Disruptive technology and securities regulation. Fordham Law Review, v. 84, n. 3, p. 977, 2015. Disponível em: <http://ir.lawnet.fordham.edu/flr/vol84/iss3/6>. Acesso em: 04 nov. 2018.

${ }^{3}$ Nesse sentido, vide: FOX, Merritt B.; GLOSTEN, Lawrence R.; RAUTERBERG, Gabriel V. The new stock market: sense and nonsense. Duke Law Journal, v. 65, n. 2, p. 199, Nov. 2015. Disponível em: $<$ https://papers.ssrn.com/sol3/papers.cfm?abstract_id=2580002>. Acesso em: 17 dez. 2018. E também: O'HARA, Maureen. High frequency market microstructure. Journal of Financial Economics, Rochester, v. 116, n. 2, $257, \quad$ May $2015 . \quad$ Disponível $<$ https://www.sciencedirect.com/science/article/pii/S0304405X15000045>. Acesso em: 17 dez. 2018.

${ }^{4}$ Uma breve definição de Guilherme Tadiello, a título introdutório, assim sintetiza o HFT: "O HFT é caracterizado pelo uso de ferramentas tecnológicas altamente sofisticadas e de algoritmos de computador para a rápida comercialização de ativos financeiros. Tem como principal vantagem competitiva a velocidade, destacando-se a sensibilidade à latência, alto giro e elevada taxa de cancelamento." OPA e algoritmos de trading: CVM debate temas durante a Semana Mundial do Investidor 2017. CVM - Comissão de Valores Mobiliários, $\quad$ Notícias, $\quad 052017.20$ Disponível $<$ http://www.cvm.gov.br/noticias/arquivos/2017/20171005-2.html>. Acesso em: 17 dez. 2018. 
no mercado secundário, nas últimas décadas. ${ }^{5}$ Seu desenvolvimento aconteceu na esteira das mudanças tecnológicas implementadas nos mercados de valores mobiliários de todo o mundo em que ocorreu a substituição das negociações processadas manualmente pelas negociações eletrônicas automatizadas. ${ }^{6}$

Essa técnica de negociação eletrônica, ${ }^{7}$ autônoma, em grande parte, em relação à atividade humana ${ }^{8}$, veio a instrumentalizar parcela significativa das operações cursadas hoje. Em adequação à realidade, a única bolsa em atividade no Brasil fez investimentos de vulto para prover serviços de tecnologia. ${ }^{9}$

Para as instituições intermediárias do mercado de bolsa (os "intermediários"), o impacto não foi menor. A inovação tecnológica na seara da eletronificação, da automação e

"The secondary market for U.S.-listed equities has changed dramatically in recent years. In large part, the
change reflects the culmination of a decades-long trend from a market structure with primarily manual
trading to a market structure with primarily automated trading."SEC - SECURITIES AND EXCHANGE
COMMISSION. 17 CFR Part 242. Concept release on equity market structure. Proposed Rule. Release No.
34-61358. Washington, D.C.: [s.n.], 2010. v. 75, p. 3594 .
"HFT is one of the key developments stemming from technological advances. It can be traced back to as early
as 2000 and is part of a long trend toward increasing trading automation. However, in the last few years it
has become a quantitatively significant feature of modern financial markets." IOSCO - INTERNATIONAL
ORGANIZATION OF SECURITIES COMMISSIONS. Technical Committee of the International
Organization of Securities Commissions. Regulatory Issues Raised by the Impact of the Technological
Changes on Market Integrity and Efficiency: Final Report. FR09/11, Oct. 2011. p. 20. Disponível em:
$<$ http://www.iosco.org/library/pubdocs/pdf/IOSCOPD361.pdf $>$. Acesso em: 01 jan. 2014 .
6Vide, por exemplo, um relato sobre o processamento manual das negociações no mercado de valores
mobiliários dos Estados Unidos:
"Until about a decade ago, most exchange-traded instruments in the U.S. were traded in a physical, paper-
based environment. Orders were called in by telephone, transcribed by humans and passed on to others for
execution, confirmation, and settlement. During each step, a person would look at the order and, knowing
where the market was trading, make a value judgment as to whether a clerical error might have been made.
Certainly, errors still occurred, but ample opportunities existed to detect and correct them. (...)." CLARK,
Carol. How to keep markets safe in the era of high-speed trading. Chicago Fed Letter, The Federal Reserve Bank of Chicago, n. 303, p. 2, out. 2012. Disponível em: $<$ https://www.chicagofed.org/ /media/publications/chicago-fed-letter/2012/cfloctober2012-303-pdf.pdf >. Acesso em: 17 dez. 2018.

${ }^{7}$ Estudo do BIS de 2001 forneceu as bases para uma conceituação ainda hoje válida de negociação eletrônica: "In broad terms, this refers to any use of electronic means of sending orders (bids and offers) to the market, electronic order routing, automated centralised execution and subsequent dissemination of price and volume information." BIS - BANK FOR INTERNATIONAL SETTLEMENTS. Committee on the Global Financial System. The implications of electronic trading infinancial markets. Basel: [s.n.], 2001. 32 p. Disponível em: $<$ https://www.bis.org/publ/cgfs16.htm>. Acesso em: $17 \mathrm{dez} .2018$.

${ }^{8}$ A negociação com algoritmo, que é o suporte tecnológico do HFT, como veremos no item 2.1 abaixo, é assim definida na Diretiva 2014/65/EU do Parlamento Europeu e do Conselho sobre mercados de instrumentos financeiros de 15 de maio de 2014 (também conhecida como "Markets in Financial Instruments Directive" ou "MiFID II"), artigo 4, item 1:

“(39) 'algorithmic trading' means trading in financial instruments where a computer algorithm automatically determines individual parameters of orders such as whether to initiate the order, the timing, price or quantity of the order or how to manage the order after its submission, with limited or no human intervention, and does not include any system that is only used for the purpose of routing orders to one or more trading venues or for the processing of orders involving no determination of any trading parameters or for the confirmation of orders or the post-trade processing of executed transactions; (...)"

${ }^{9}$ Vide item 3.2 deste trabalho. 
dos sistemas de comunicação alteraram o papel destes agentes. ${ }^{10}$

E para os demais agentes do mercado de valores mobiliários, o que a mecanização na colocação de ordens e no monitoramento das ofertas, a maior rapidez no fluxo de dados e o aumento no volume de mensagens, dentre outras tantas mudanças, representam?

Materiais do mundo todo examinam as repercussões da inserção do HFT no mercado. Alguns dos efeitos benéficos desse modo de negociação seriam a possibilidade de redução do valor cobrado pela prestação de serviço pelos intermediários do mercado e pelas bolsas, ${ }^{11}$ maior liquidez dos valores mobiliários em negociação ${ }^{12}$, a formação mais justa dos preços $^{13}$ e o equilíbrio entre os preços de um valor mobiliário em diferentes ambientes de negociação em razão de operações de arbitragem. ${ }^{14}$ Em contrapartida, apontam-se preocupações como, por exemplo, a seleção adversa imposta pela atividade do HFT sobre os sujeitos não usuários, a inexistência de incentivos para o HFT considerar o ativo em relação ao seu valor fundamental gerando distorções no processo de formação de preços e o risco de falhas tecnológicas ameaçarem a estabilidade de mercado. ${ }^{15}$

Reguladores, autorreguladores, instituições relacionadas ao mercado de valores mobiliários, estudos científicos, os meios de notícias e até a literatura de cunho jornalístico apregoam a necessidade de se criar normas para a utilização dessa forma recente de fazer negócios em bolsa. ${ }^{16}$ A motivação frequente dessa necessidade costuma residir em alguns episódios de grande repercussão envolvendo a utilização do HFT. ${ }^{17}$ Um tom de maniqueísmo

\footnotetext{
${ }^{10}$ A questão é abordada em detalhe nos itens 1.2, 2.2 e 3.1 deste trabalho.

${ }^{11}$ Sobre a questão da redução dos custos de transação, vide: UNITED KINGDOM - UK. The Government Office for Science. Foresight: the future of computer trading in financial markets. Final Project Report. London, 2012. 20 p. $52 . \quad$ Disponível em: $<$ https://assets.publishing.service.gov.uk/government/uploads/system/uploads/attachment_data/file/289431/ 12-1086-future-of-computer-trading-in-financial-markets-report.pdf $>$. Acesso em: 18 dez. 2018.

${ }^{12}$ Sobre a questão da liquidez, vide: TANNOUS, Thiago Saddi. Proteção à liquidez no mercado de capitais brasileiro. São Paulo, Quartier Latin, 2018. p. 85.

${ }^{13}$ Sobre a questão, vide a entrevista de Peter Nabicht a Daniel P. Collins: COLLINS, Daniel P. High frequency traders: fall guys or felons? Futures Magazine: market structure, p. 14, May 2014. Disponível em: $<$ http://www.futuresmag.com/2014/05/01/high-frequency-traders-fall-guys-or-felons $>$. Acesso em: 17 dez. 2018.

${ }^{14}$ MICHAELS, Dave; PHILIPS, Matthew; BRUSH, Silla. Slow Cop, Fast Beat: SEC takes its time on highfrequency trading rules: the SEC is taking its time studying the market before issuing rules to curb speed traders. 2014. Bloomberg Business Week. Disponível em: <https://www.bloomberg.com/news/articles/201404-10/sec-takes-its-time-on-high-frequency-trading-rules>. Acesso em: 17 dez. 2018.

${ }^{15}$ FOUCAULT, Thierry. Where are the risks in high frequency trading? Financial stability in the digital era. Banque de France. Financial Stability Review, n. 20, p. 59-64, Apr. 2016.

16"High-frequency trading, dark pools, front-running, phantom orders, short selling - the way securities are traded ranks high among today's regulatory challenges. Thanks to a steady stream of news reports, investor complaints and public investigations, calls for the government to intervene and impose order have become commonplace, both in financial and academic circles." FLECKNER, Andreas Martin. Regulating trading practices. The Oxford Handbook of Financial Regulation, Oxford, p. 596-630, Dec. 2015. Disponível em: $<$ https://papers.ssrn.com/sol3/papers.cfm?abstract_id=2476950>. Acesso em: 17 dez. 2018.

${ }^{17}$ Estes eventos serão discutidos no Capítulo 1.
} 
permeava as discussões iniciais sobre o tema, ${ }^{18}$ assim como um alarmismo fundado nos referidos episódios.

Contudo, passadas quase duas décadas do surgimento do HFT, os eventos se mostraram, ao menos até agora, isolados, a ferramenta se consolidou na prática negocial e a preocupação deu lugar a investigações mais imparciais. ${ }^{19}$

Nesse cenário, teria o direito do mercado de valores mobiliários, para melhor compreender as questões relacionadas ao momento presente, buscado entender como a inovação e a tecnologia transformaram a operacionalização do negócio jurídico de compra e venda de valores mobiliários em bolsa? Qual a significação, para o Direito Brasileiro, do arcabouço tecnológico organizado no mercado de valores mobiliários nacional para o HFT? Teria o direito do mercado de valores mobiliários buscado recursos para compreender e para formular um tratamento adequado e completo à nova conformação do mercado e ao objeto que desencadeou essa transformação?

A partir da análise destas questões, como seria um regime regulatório prudencial adequado para o HFT, pensando no objetivo especifico da integridade de mercado?

No intuito de responder a estas questões, o presente trabalho cumpre, de início, a missão de observar o HFT a partir de seu fato como inovação tecnológica, delineando as repercussões que seu emprego impõe ao mercado de valores mobiliários. Assim, parte da identificação e compreensão das condições de existência da figura. Trata-se de processo essencial para posterior desenvolvimento de uma abordagem jurídica.

O cotidiano das operações de bolsa utilizando o HFT é permeado por instrumentos e estruturas tecnológicas que precisam ser observados, conhecidos e analisados. Entidades administradoras de sistemas de negociação do mundo inteiro se organizaram para criar

\footnotetext{
${ }^{18}$ Exemplo disso podiam ser vistos nos títulos sugestivos de diversos materiais:

(i) MACINTOSH, Jeffrey G. Hign frequency traders: angels or devils? C.D. Howe Institute Commentary, Toronto, n. 391, p. 1-29, out. 2013. Disponível em: $<$ https://papers.ssrn.com/sol3/papers.cfm?abstract_id=2340673>. Acesso em: 17 dez. 2018.;

(ii) COLLINS, Daniel P. High frequency traders: fall guys or felons?, cit., p. 14-17;

(iii) MENKVELD, Albert J. HFT good or bad?: a literature survey. June 1, 2016. Disponível em: $<$ https://albertjmenkveld.com/2016/06/01/hft-good-or-bad-a-literature-survey/>. Acesso em: 17 dez. 2018.

${ }^{19}$ Sobre a falta de fundamento concreto para as discussões travadas sobre o HFT, Menkveld anota que: "The public debate on HFTs raged since 2009 thriving mostly on conjectures and fears." MENKVELD, Albert J. The economics of high-frequency trading: taking stock. Annual Review of Financial Economics, Amsterdã, v. 8, p. 5, June 2016. Disponível em: <https://ssrn.com/abstract=2787542>. Acesso em: 29 jul. 2018.

E sobre a necessidade atual de se examinar o HFT de forma mais objetiva, FOX et al assim asseveram:

"It is time to step back and take a serious, dispassionate look at how the new stock market functions and the implications of the regulatory choices we face going forward." (FOX, Merritt B.; GLOSTEN, Lawrence R.; RAUTERBERG, Gabriel V. The new stock market: sense and nonsense, cit., p. 196).
} 
formas de recepcionar esta inovação. Intermediários precisaram repensar suas funções históricas. Alguns perfis de investidores precisaram sair da zona de conforto baseada na dependência no intermediário e buscar compreender o novo jeito de operar em bolsa, enquanto que, para outros agentes, abriu-se um novo campo de negócios. O Direito também precisa se familiarizar com estas mudanças.

Em um segundo momento, o presente estudo apresenta nossos esforços no sentido de refletir sobre alguns aspectos do design ideal do sistema regulatório para endereçar a feição do HFT como inovação tecnológica sob uma perspectiva prudencial, a luz do objetivo da integridade do mercado.

Para a sociedade, as partes mais visíveis da atividade do Direito consistem na criação de regras para as interações da vida onde problemas possam afetar o bom andamento das relações sociais, ${ }^{20}$ assim como na imposição de sanções para condutas consideradas nocivas para a coletividade. ${ }^{21}$

Contudo, a tarefa do Direito é mais ampla. Como ciência social aplicada, deve observar os fenômenos da vida e identificar os problemas que efetivamente reclamam a criação de uma tutela jurídica específica. Na sequência, deve avaliar quais as estratégias de configuração da atividade jurídica apresentam soluções mais adequadas para tais problemas. A edição de normas expressas e a aplicação de punições se afiguram como alternativas possíveis, mas não são as únicas.

A ordenação do mercado financeiro em sentido lato aceita essa ideia de tarefa mais ampla do direito. Isso se reflete na sistematização comumente utilizada de suas normas em

\footnotetext{
${ }^{20}$ Essa noção é histórica. Custódio identifica no tratado medieval de Nicole Oresme sobre a moeda a ideia de regras como forma de atingimento do bem-estar social: "Na primeira parte, o autor expõe que uma comunidade política deve ter leis e ordenações próprias e particulares que organizem a vida social de modo a propiciarem o bem viver. Essas leis e prescrições devem ser firmes e estáveis, e por consequência, não sujeitas a alterações recorrentes." Assim, as regras sobre a moeda não devem ser alteradas sem necessidade. CUSTÓDIO, Sueli Sampaio Damin. Política e teoria monetária em Nicole Oresme. In: CARVALHO, Marcelo; ÉVORA, Fátima R.; TOSSATO, Claudemir Roque; PESSOA JR., Oswaldo (Orgs.). Filosofia da ciência e da natureza. 26. ed. São Paulo: ANPOF, 2015. p. 63. (Coleção XVI Encontro ANPOF). Disponível em: $<$ http://www.anpof.org/portal/images/Colecao_XVI_Encontro_ANPOF/Filosofia_da_cincia_e_da_natureza.p df>. Acesso em: 17 dez. 2018.

${ }^{21}$ Pessoas como Martha Stewart, Bernard Madoff e Naji Nahas; casos como o da Fazendas Reunidas Boi Gordo; práticas como insider trading e, em se tratando de HFT, o layering e o spoofing, são figuras recorrentes lembradas pelas pessoas em se tratando de mercado de valores mobiliários.
} 
regras prudenciais, ${ }^{22}$ de condutas $^{23}$ e sistêmicas. ${ }^{24}$

Nosso estudo tem por enfoque a regulação prudencial. Segundo a lição de Yazbek, ela trata “(...) muito mais da adoção de políticas sadias de gestão das atividades financeiras e de organização da empresa do que de regras específicas de conduta negocial." ${ }^{25}$ Nossa escolha se funda em dois motivos. O primeiro, é em razão da menor atenção conferida ao tema. O segundo, diz respeito ao estágio de desenvolvimento do mercado brasileiro. A técnica de negociação em alta frequência é recente no mercado nacional. Pela abordagem do tema estar em fase inicial, é interessante que se construa desde já uma estrutura robusta que enderece questões prudenciais. Mediante a implementação de uma organização eficiente, a estrutura do mercado de valores mobiliários nacional pode buscar tanto se antecipar a problemas como fomentar a confiança do público investidor na sua higidez.

Tendo em vista a complexidade do objeto em exame somado ao enfoque específico escolhido, sistematizamos, abaixo, em detalhe, as delimitações deste trabalho, muitas das quais já foram acima esboçadas, mas que passamos a detalhar.

O objeto de interesse deste estudo recai especificamente sobre os reflexos da inserção de tecnologia inovadora - o HFT - na operacionalização do negócio jurídico de compra e venda de valores mobiliários em bolsa ${ }^{26}$ e das implicações que isto tem para a entidade administradora de sistema de negociação, para os intermediários autorizados a acessar esses sistemas e para os investidores, assim como o papel da regulação prudencial sobre estes

\footnotetext{
${ }^{22} \mathrm{Em}$ breve definição para direito do mercado financeiro, mas também válida para o direito do mercado de capitais, vide:

"A regulação prudencial possui caráter mais preventivo, procurando delinear regras que mantenham a higidez do setor bancário e do sistema financeiro como um todo, de modo que, embora seja apresentada de maneira separada, atua de maneira complementar à regulação sistêmica." PINTO, Gustavo Mathias Alves. Regulação sistêmica e prudencial no setor bancário brasileiro. São Paulo: Almedina, 2015. p. 2.

23“'A regulação de condutas ou 'transacional' diz respeito, como anteriormente esclarecido, às práticas adotadas pelos agentes de mercado nas suas relações negociais. Para tal, são criadas regras diversas, autorizando ou vedando determinadas práticas ou, ainda, delimitando operações e estruturas de mercado. (...)" YAZBEK, Otavio. Regulação do mercado financeiro e de capitais. 2. ed. São Paulo: Elsevier; Campus, 2009. p. 223.

24“'A regulação sistêmica, como acima se referiu, é implementada a partir de uma rede de proteção para o sistema financeiro, destinada a impedir a ocorrência daquelas externalidades relacionadas ao alto grau de integração entre as instituições, sobretudo no caso das instituições bancárias. Não obstante, como a seguir se verá, não raro regimes típicos de regulação sistêmica são aplicados também a outras instituições. Tal extensão se justifica, inicialmente, pela já referida integração entre atividades, em razão da qual uma falha localizada em uma das instituições de um conglomerado pode levar a problemas em outras, mas também pela gravidade de problemas ocorridos em algumas daquelas outras instituições e pela extensão dos efeitos daí decorrentes." Id. Ibid., p. 231.

${ }^{25}$ Id. Ibid., p. 194.

${ }^{26}$ Considerando que o HFT é técnica ordinariamente empregada em operações de bolsa, tratamos de atividade que é realizada no mercado secundário entre investidores, ou seja, no ambiente em que possíveis compradores e vendedores se encontram para negociar seus valores mobiliários.
} 
agentes no delineamento de um mercado íntegro no Brasil.

Uma segunda delimitação de nosso objeto, como já adiantamos, diz respeito a uma área que costuma atrair menos interesse daqueles que estudam a ordenação do mercado de bolsa: a regulação prudencial. Nessa perspectiva, estudamos:

(i) no âmbito da microestrutura de mercado organizada no Brasil, os agentes envolvidos, as interações entre eles e as regras prudenciais a que estão submetidos; e

(ii) a infraestrutura posta em funcionamento pela única bolsa de valores mobiliários em atividade hoje no país, a B3 S.A. - Brasil, Bolsa, Balcão (a “B3”), identificando os meios e sistemas implementados para que as negociações em alta frequência ocorram.

Ressalte-se: é a questão da estruturação de meios, sistemas e relações para que essas operações sejam perfectibilizadas que nos interessa diretamente ${ }^{27}$. Nosso interesse recai sobre a modelagem organizacional ideal para realização das operações pensando no atendimento do objetivo da 'integridade de mercado', assim entendida como “( ...) a medida em que um mercado opera de maneira que seja, e que seja percebida como, justa e ordenada e onde as regras em vigor são estabelecidas e cumpridas por reguladores de forma a fomentar a confiança e participação no mercado." 28

As intercorrências nocivas na atividade ordinária de mercado na forma de ilícitos, crimes e a deturpação da figura em exame (preocupação típica da regulação de condutas e de interesse de medidas sancionadoras) são abordadas apenas na medida em que auxiliem no exame dos temas objeto deste trabalho. Nessa linha, os problemas relativos ao estudo dos chamados 'abusos de mercado' fogem do nosso escopo.

\footnotetext{
${ }^{27}$ Isto está em linha com o enfoque do MIFID II que se preocupa em regular através da fixação de "requisitos organizacionais" para "firmas de investimento" e "ambientes de negociação":

"The rules governing high-frequency-trading will impose a strict set of organisational requirements on investment firms and trading venues, and the provisions regulating the non-discriminatory access to central counterparties (CCPs), trading venues and benchmarks are designed to increase competition." ESMA EUROPEAN SECURITIES AND MARKETS AUTHORITY. MIFID II. 2017. Disponível em: $<$ https://www.esma.europa.eu/policy-rules/mifid-ii-and-mifir>. Acesso em: 27 jul. 2018.

${ }^{28}$ Tradução livre de: "Market integrity is the extent to which a market operates in a manner that is, and is perceived to be, fair and orderly and where effective rules are in place and enforced by regulators so that confidence and participation in the market is fostered." IOSCO - INTERNATIONAL ORGANIZATION OF SECURITIES COMMISSIONS. Technical Committee of the International Organization of Securities Commissions. Regulatory Issues Raised by the Impact of the Technological Changes on Market Integrity and Efficiency: Final Report. FR09/11, Oct. 2011, cit., p. 9.
} 
Igualmente foge do nosso escopo a atenção aos estudos sobre a 'eficiência de mercado, ${ }^{29}$ ou 'qualidade de mercado', ${ }^{30}$ que se debruçam sobre a investigação de temas como formação de preço, liquidez, volatilidade, custos de transação, transparência na informação. São assuntos frequentes da literatura internacional e já são parte da preocupação da academia nacional. Enquanto o estudo de tal tema presta contas para um público maior de envolvidos sobre problemas de maior visibilidade, optamos por examinar as fundações sobre as quais o mercado se constrói, questão prévia às discussões sobre eficiência e qualidade das negociações com ativos.

Em relação aos sujeitos a serem tratados, optamos por realçar a interação entre os agentes diretamente envolvidos desde a fase do pré-trade (ou pré-trading) até a fase do encontro das ofertas, o trade (ou trading) ${ }^{31}$ : a entidade administradora de sistema de negociação (a bolsa) e os intermediários autorizados a acessar diretamente o sistema de negociação (atividade exercida, na maioria das vezes, pelas sociedades corretoras de valores mobiliários - as "corretoras" - e pelas sociedades distribuidoras de valores mobiliários - as distribuidoras -). ${ }^{32}$ E porque a inovação tecnológica impactou a realidade das operações em questão, o papel dos investidores comitentes precisa ser revisto.

Tratando-se de tema complexo e diante da necessidade de construção de uma base sólida, entendemos que a análise destes players permite um ponto de partida para estudos

\footnotetext{
${ }^{29}$ Market efficiency refers to the ability of market participants to transact business easily and at a price that reflects all available market information. Factors considered when determining if a market is efficient include liquidity, price discovery and transparency. IOSCO - INTERNATIONAL ORGANIZATION OF SECURITIES COMMISSIONS. Technical Committee of the International Organization of Securities Commissions. Regulatory Issues Raised by the Impact of the Technological Changes on Market Integrity and Efficiency: Final Report. FR09/11, Oct. 2011, cit., p. 9.

${ }^{30}$ Nos termos do relatório UK, qualidade de mercado ou 'market quality', em inglês, é "the general term used to describe the liquidity, transaction costs and price efficiency of a Market." UNITED KINGDOM - UK. The Government Office for Science. Foresight: the future of computer trading in financial markets. Final Project Report, cit., p. 42.

${ }^{31}$ Nessa linha, das fases de negociação, examinaremos a fase pré-trade (ou pré-trading) e a fase do trade (ou trading). Sobre as etapas da negociação, vide o seguinte material produzido pela CVM:

"8.3.1. As etapas da negociação

O processo que envolve a compra e a venda, tanto no mercado primário como no secundário, pode ser dividido em três fases: pré-negociação, negociação e pós-negociação.

Pré-negociação (Pré-trading)

Compreende os serviços de informação ao mercado e as vendas de sinais e cotações.

Negociação (Trading)

Ocorre quando os investidores, representados pelas Corretoras ou Distribuidoras, enviam ordens de compra e venda para o pregão eletrônico - sistema de negociação. Para que a efetivação desse negócio seja concluída, é necessária uma terceira fase, conhecida como pós-negociação.”

A fase do pós-trade (ou pós-trading), definida nos termos abaixo, não é enfoque deste estudo:

"Pós-negociação (Pós-trading) Ocorre com as seguintes etapas da compensação, liquidação e custódia (guarda dos ativos).” CVM - COMISSÃO DE VALORES MOBILIÁRIOS. Mercado de valores mobiliários. Rio de Janeiro: Comissão de Valores Mobiliários, 2014. p. 243.

${ }^{32}$ Abordaremos estas instituições mais adiante no trabalho.
} 
futuros dos demais participantes envolvidos na questão do HFT em seu aspecto tecnológico. Outros agentes ${ }^{33}$ também são levados em conta na medida em que entrarem em contato com os sujeitos e objeto sob enfoque deste estudo. Não adentraremos, contudo, nas especificidades dos problemas particulares que enfrentam na atualidade. ${ }^{34}$

Outra baliza importante de nosso estudo diz respeito ao alcance em utilizaremos a expressão 'regulação'. O direito do mercado de valores mobiliários lida com a inovação financeira. Com isso, precisa ser também flexível, criativo e inovador ao pensar suas formas de interferência. A forma tradicional de regular, qual seja, a imposição de regras e punições, é, nessa seara, apenas um dos instrumentos possíveis para evitar ou sanar problemas.

A própria análise da competência do regulador nacional hoje nos mostra essa plasticidade: pode o regulador nacional normatizar, fiscalizar (e dentro disso, supervisionar) e punir. Mais recentemente, tem sido dada atenção à atividade de fomento. ${ }^{35}$ Tudo isso é interferência estatal em virtude de questões que reclamam atenção do direito, atenção essa que pode se concretizar, dentre outras formas, com regras, orientações, acompanhamento, estudos, formação educacional e, como se verá, mediante internalização do direito na própria ferramenta. ${ }^{36}$

Utilizamo-nos, portanto, de uma acepção ampla de regulação, como atividade ordenadora realizada pelo Estado, que, para tanto, emprega diversas ferramentas. E, da "caixa de ferramentas" 37 disponível, ensaiamos uma proposta sobre quais o direito brasileiro

${ }^{33}$ Como instituições relacionadas ao pós-trade, empresas prestadoras de serviços de tecnologias (as "Fintechs"), além do mercado de valores mobiliários como um bem em si.

${ }^{34}$ Nesse sentido, pode-se pensar, exemplificativamente, que:

(i) A relação das instituições de pós-trade com o HFT precisariam examinar problemas que são posteriores à fase de celebração do negócio, como a liquidação, compensação e depósito de ativos;

(ii) A relação entre empresas prestadoras de serviços de tecnologia e o HFT precisaria examinar a real extensão do poder que a atividade das chamadas fintechs tem hoje sobre os programas, mecanismos e sistemas envolvidos na negociação em alta frequência; e

(iii) A relação entre o mercado de valores mobiliários como um bem em si precisaria examinar a conveniência ou não da dispersão (ou "fragmentação") das bolsas face aos problemas já existentes em razão da inovação tecnológica.

${ }^{35}$ Sobre a função de fomento:

“O artigo $4^{\circ}$ da Lei n. ${ }^{\circ}$ 6385/1976, em seus incisos I e II, lança a função de fomento da autarquia. Trata-se da adoção de medidas que buscam o desenvolvimento do mercado, a fim de estimular e promover sua expansão, bem como seu funcionamento eficiente e regular. São atividades de ordem institucional, que visam a divulgar práticas salutares entre os agentes, além de promover investimentos no mercado.

Como exemplo, pode-se salientar o serviço de atendimento ao público para fornecimento de informações, bem como os programas de educação, tais como concurso de monografias sobre temas do mercado e convênio com universidades." ROSA, Maria Eduarda Fleck da. O Poder Normativo da Comissão de Valores Mobiliários. 2012. Dissertação (Mestrado) - Programa de Pós-Graduação em Direito da Faculdade de Direito da Universidade de São Paulo, São Paulo, 2012. p. 97.

${ }^{36}$ Vide Capítulo 5.

${ }^{37}$ A IOSCO emprega as expressões "regulatory tools" e "regulatory toolkit". IOSCO - INTERNATIONAL ORGANIZATION OF SECURITIES COMMISSIONS. Technical Committee of the International Organization of Securities Commissions. Regulatory Issues Raised by the Impact of the Technological Changes on Market Integrity and Efficiency: Final Report. FR09/11, cit., p. 33. 
deve considerar escolher para melhor tratar o HFT em uma perspectiva prudencial. ${ }^{38}$

Quanto à relevância do presente estudo para a ciência jurídica, já em 2010 a SEC assim se manifestava sobre a importância do HFT como um componente da estrutura do mercado contemporâneo: “(...) HFT is a dominant component of the current market structure and is likely to affect nearly all aspects of its performance." 39

Além dos efeitos hipotéticos que se investiga que possam ser causados pelo HFT no mercado, o uso desta forma de operação já resultou em ou já foi apontado como motivo de crises concretas que causaram efeitos nocivos ao mercado de valores mobiliários. No Brasil, não é diferente. Os impactos do uso do HFT também já preocupam o mercado nacional. ${ }^{40}$

Diante do crescente espaço que as negociações com HFT vem tomando, ${ }^{41}$ combinado com os potenciais efeitos e as possibilidades de distúrbios à integridade de mercado, é imperativo que o direito brasileiro busque maior contato com a intrincada estrutura tecnológica posta em atividade no mercado de valores mobiliários nacional para permitir o curso desta nova forma de negociar, direcionamento que este estudo assume.

Se analisar esta estrutura é parte da tarefa mais ampla de refletir sobre qual seria o tratamento regulatório adequado ao tema, cabe aqui apontar pelo menos duas justificativas

\footnotetext{
${ }^{38}$ Já nos é caro há algum tempo examinar a diversidade de ferramentas de que dispõe o direito do mercado de valores mobiliários para melhor cumprir a sua função. Em estudo anterior, examinamos como a interposição de sujeito (o 'intermediário'), qualificado pelo regulador como determinada figura (o 'gatekeeper'), colocava-se como agente de condutas benéficas ao mercado. Neste trabalho, mais uma vez damos vazão à nossa inquietação sobre como a criatividade jurídica pode ser posta a serviço de um regime jurídico melhor. HAENSEL, Taimi. A figura dos gatekeepers: aplicação às instituições intermediárias do mercado organizado de valores mobiliários brasileiro. 2014. Dissertação (Mestrado em Direito) - Programa de Pós-Graduação em Direito da Faculdade de Direito da Universidade de São Paulo, São Paulo, 2014. Disponível em: $<$ http://www.teses.usp.br/teses/disponiveis/2/2132/tde-04032015-083153/en.php>. Acesso em: 18 dez. 2018. HAENSEL, Taimi. A figura dos gatekeepers. 1. ed. São Paulo: Almedina, 2014. p. 286.

39،(...)." SEC - SECURITIES AND EXCHANGE COMMISSION. 17 CFR Part 242. Concept release on equity market structure. Proposed Rule. Release No. 34-61358, cit., v. 75, p. 3606.

${ }^{40}$ O Relatório da CVM referente ao segundo semestre de 2017 assim deu realce ao tema, noticiando a abertura de um segundo processo na autarquia referente a prática abusiva:

"1.3. Acompanhamento dos trabalhos e casos de destaque

1.3.1. Spoofing

No semestre foi instaurado na CVM o segundo processo envolvendo a ocorrência de spoofing, no qual a uma gestora de recursos e um banco foram acusados de manipulação por utilizarem estratégias de spoofing em ofertas registradas via DMA, no período de 27.07.2015 a 29.02.2016.”

E assim relatou as atividades na seara da autorregulação pela BSM:

"Como decorrência das medidas a respeito, até o encerramento do $2^{\circ}$ semestre de 2017 , sete casos de spoofing haviam sido concluídos por meio de Termos de Compromisso, encontrando-se em andamento dois outros casos." CVM - COMISSÃO DE VALORES MOBILIÁRIOS. Supervisão Baseada em Risco: relatório semestral, julho-dezembro, 2017. Aprovado pelo Comitê de Gestão de Riscos em 16/04/2018. Rio de Janeiro, 2017. p. 106-107. Disponível em: $<$ http://www.cvm.gov.br/export/sites/cvm/menu/acesso_informacao/planos/sbr/Relatorio_Semestral_julhod ezembro_2017.pdf $>$.

${ }^{41}$ Examinaremos isso no Capítulo 1.
} 
para promovermos esta reflexão sobre o recorte específico do viés tecnológico do HFT.

A primeira, de ordem geral, é que uma das principais críticas sofridas na atualidade por normas feitas emergencialmente, após a ocorrência de crises de grandes repercussões no mercado de valores mobiliários, é de que elas dão margem ao oportunismo dos agentes que participam de sua elaboração e que seu conteúdo não teve tempo suficiente para ser discutido e amadurecido, o que resulta na inadequação de certas medidas previstas. ${ }^{42} 43$

Acresce a isso que é inerente à condição de inovação tecnológica do HFT a dificuldade em compreendê-lo, assim como a possibilidade de ocorrência de $\operatorname{erros}^{44}$ e de descoberta de novas aplicações não inicialmente previstas para a ferramenta ${ }^{45}$.

Nessa esteira, este estudo busca contribuir para o debate sobre que modelo de abordagem é adequado ao tratamento jurídico do HFT no Brasil, evitando os problemas que ocorrem quando se impõe medidas sem a devida especialização técnica sobre a matéria, sem a devida reflexão e sem a participação do público impactado pela medida.

A segunda razão é que o direito brasileiro tem a inovação e tecnologia como ferramentas $^{46}$ a serviço dos valores desenvolvimentistas insculpidos na Constituição Federal. ${ }^{47} 48$ Nesse sentido, o tratamento do HFT não requer apenas esforços para propiciar um ambiente adequado para a realização de negócios privados: é parte da tarefa maior de contribuir para o crescimento do país. Some-se a isto que o mercado de valores mobiliários, como parte do patrimônio interno, por si só, reclama uma preocupação mais ampla do que aquela que pode lhe dedicar o regime privatístico. Erigir um regime jurídico prudencial do HFT no Brasil atende melhor essas demandas do que a construção de um regime reativo.

\footnotetext{
${ }^{42}$ A Lei Sarbanes-Oxley e a Lei Dodd-Frank seriam exemplos de normas elaboradas neste contexto.

Vide, por exemplo, a crítica de Roberta Romano em relação à Lei Sarbanes-Oxley em The Sarbanes-Oxley Act and the Making of Quack Corporate Governance. ROMANO, Roberta. The Sarbanes-Oxley Act and the making of quack corporate Governance. Yale Law \& Economics Research Paper, New Haven, n. 297, p. 234 , Sept. 2004. Disponível em: <https://papers.ssrn.com/sol3/papers.cfm?abstract_id=596101>. Acesso em: 18 dez. 2018. E, sobre a Lei Dodd-Frank, vide: BAINBRIDGE, Stephen M. Dodd-Frank: Quack Federal Corporate Governance Round II. UCLA School of Law, Law-Econ Research Paper, Los Angeles, n. 10-12, p. 41, Sept. 2010. Disponível em: <https://papers.ssrn.com/sol3/papers.cfm?abstract_id=1673575>. Acesso em: 18 dez. 2018.

${ }^{43}$ A proposta de imposição de tributação sobre operações com HFT seria a mais recente amostra desse tipo de reação apressada. Isto será examinado em maior detalhe no item 1.4 deste trabalho.

${ }^{44}$ Vide item 1.3 deste trabalho.

${ }^{45}$ Vide item 2.1 deste trabalho.

${ }^{46}$ Tem-se, hoje, um intrincado e extenso sistema legislativo dedicado à ciência, tecnologia e inovação. Nesse sentido, vide, de forma não exaustiva: Lei 10.973/2004 ("Lei de Inovação"); Lei 11.080/2004 ("Lei da ABDI"); Lei 11.196/2005 (“Lei do Bem”); Lei 11.487/2007 (“Lei de incentivo à pesquisa e inovação"); e Lei 13.243/2016 ("Marco Legal da Ciência, Tecnologia e Inovação").

${ }^{47}$ Nesse sentido vide: GRAU, Eros Roberto. A Ordem Econômica na Constituição de 1988 (interpretação e crítica). 14. ed. rev. e atual. São Paulo: Malheiros Ed., 2010.

${ }^{48}$ Vide arts. 218, 219, 219-A, 219B da Constituição Federal. Note-se que a Constituição Federal, com redação dada pela EC 85/2015, acrescentou a expressão ‘inovação’ ao capítulo sobre ciência e tecnologia.
} 
Nosso estudo foi elaborado com base em pesquisa de materiais diversos, partindo da revisão da doutrina de Direito Estrangeiro (farta $)^{49}$ e do Direito Brasileiro (em crescimento) $)^{50}$ sobre o HFT.

Em termos de materiais institucionais, nossa pesquisa debruçou-se sobre o estudo de normas, diretivas, manifestações da lavra de reguladores, autorreguladores e de outras instituições de interesse para o mercado de valores mobiliários nacional e internacional. ${ }^{51}$

Consultamos a literatura produzida pela economia, administração, finanças, contabilidade, tecnologia da informação, sociologia e outras áreas correlatas, de forma a permitir o entendimento sobre os conceitos, relações e efeitos que o Direito pretende regular. ${ }^{52}$

O tema é recente no mercado de valores mobiliários nacional. A economia, a administração, a estatística e outras áreas de conhecimento ainda estão buscando melhor compreender as implicações desta forma recente de operar no mercado secundário brasileiro. A produção científica nestas áreas encontra-se em expansão. ${ }^{53}$

\footnotetext{
${ }^{49} \mathrm{Na}$ seara do Direito Estrangeiro, bases de dados públicas (Social Sciences Research Network), bases institucionais (CAFe, do Portal de Periódicos CAPES, MISES Institut) e bases privadas (a exemplo de Lexis Nexis, EBSCO, JStore, Web of Science, Hein Online, Science Direct, Westlaw), mostraram-se ricas em artigos atualizados sobre temas de mercado de valores mobiliários no plano internacional

${ }^{50}$ No plano nacional, recorremos à pesquisa nos principais periódicos jurídicos (Revista de Direito Bancário, Revista de Direito Mercantil, Revista de Direito Empresarial, Revista de Direito das Sociedades e dos Valores Mobiliários), bases institucionais (Teses USP, Repositório Digital FGV, do Portal de Periódicos CAPES, CVM), bem como a bases de dados online privadas (RT Online) e públicas (LexML, Dedalus e Pergamum).

${ }^{51}$ A exemplo da CVM, SEC, IOSCO, ESMA, BIS, WFE e FESE. As bases de dados on line públicas de tais instituições foram acessadas para a obtenção de tais documentos.

${ }^{52}$ Bases como SSRN, EBSCO e CAFe foram acessadas no intuito de buscar tais materiais. Ainda neste escopo, foram consultadas obras físicas.

${ }^{53}$ Vide, exemplificativamente: UEMATSU, Akira Arice de Moura Galvão. Algoritmos de negociação com dados de alta frequência. 2012. Dissertação (Mestrado em Estatística) - Instituto de Matemática e Estatística, Universidade de São Paulo, São Paulo, 2012. p. 53. Disponível em: <http:/www.teses.usp.br/teses/disponiveis/45/45133/tde28042012-114138/pt-br.php>. Acesso em: 18 dez. 2018.

NUNES, Gustavo de Faro Colen. Modelo da dinâmica de um livro de ordens para aplicações em highfrequency trading. 2013. 49 p. Dissertação (Mestrado Profissional) (Programa de Mestrado Profissional em Economia)- Fundação Getúlio Vargas/EESP, São Paulo, 2013. Disponível em: $<$ http://hdl.handle.net/10438/10570>. Acesso em: 18 dez. 2018.

PONTUSCHKA, Martin. A estratégia de pares aplicada a dados de alta frequência no mercado acionário brasileiro. 2012. 46 p. Trabalho de Conclusão de Curso de Graduação (Curso de Administração) - Escola de Administração, Universidade Federal do Rio Grande do Sul, Porto Alegre-RS, 2012. Disponível em: $<$ http://hdl.handle.net/10183/73001>. Acesso em: 18 dez. 2018.

LOPES, Rodrigo Soares. High frequency trading no mercado brasileiro. 2012. Trabalho de Conclusão de Curso (MBA em Gestão de Negócios) - IBMEC Business School, Rio de Janeiro, 2012. 64 p.

ARAÚJO, Alcides Carlos de. Combinações de projeções de volatilidade baseadas em medidas de risco para dados em alta frequência. Tese (Doutorado). Faculdade de Economia, Administração e Contabilidade. Programa de Pós-Graduação em Administração. USP. São Paulo, 2016. p. 287. Disponível em: $<\mathrm{http} / /$ www.teses.usp.br/teses/disponiveis/12/12139/tde-11072016-153404/en.php>. Acesso em: 18 dez. 2018. LOPES, Rodrigo Soares. Aplicação de estratégias de high frequency trading no mercado brasileiro de dólar futuro. 2018. Dissertação (Mestrado em Controladoria e Contabilidade) - Faculdade de Economia, Administração e Contabilidade, Universidade de São Paulo, São Paulo. Disponível em: $<$ http://www.teses.usp.br/teses/disponiveis/12/12136/tde-21082018-142155/pt-br.php>. Acesso em: 18 dez. 2018.
} 
Nos últimos anos, o tema vem atraindo a atenção também de estudos jurídicos. Já se conta com trabalhos ${ }^{54}$ e $\operatorname{artigos}^{55}$ acadêmicos abordando o tema. Em linhas gerais, eles noticiam a utilização do novo mecanismo no mercado. Em sede de aprofundamento, buscam compreender o que é o HFT, bem como pontuar repercussões de seu uso para o mercado de valores mobiliários e possíveis medidas regulatórias endereçando problemas relacionados à conduta dos agentes.

O direcionamento dessas pesquisas faz sentido. Investigam aquilo que é mais premente de ser tratado do ponto de vista da pacificação social, para apaziguar a inquietação do público investidor: a desconfiança no sistema, a possibilidade de perdas patrimoniais e de ser vítima de ilícitos. Estas são as facetas mais facilmente vislumbradas pelo mercado, mas não as únicas relevantes do fenômeno.

A importância do tema no exterior já é sedimentada. Já se discute amplamente no plano internacional o que é problema em se tratando de HFT, se ele é 'bom' ou 'mal' e os efeitos disso para o mercado. $\mathrm{O}$ estado da pesquisa nacional vem acompanhando estes debates e, em linha com os modelos externos, concentrado esforços em investigar qualidade, eficiência e abusos de mercado.

É em relação a esse quadro que nosso estudo busca caminhos diversos. Como já mencionado, nosso estudo recai sobre as repercussões do contato entre a inovação tecnológica e o mercado de valores mobiliários. De forma complementar, busca um possível tratamento jurídico prudencial que se antecipe às dificuldades e aos riscos dessa interação, com o escopo de promover um mercado confiável, equitativo e ordenado, em linhas com os objetivos de um mercado íntegro.

\footnotetext{
${ }^{54}$ Vide, exemplificativamente: NODA, Margareth. Acesso eletrônico e tendências para a intermediação no mercado de valores mobiliários. Dissertação (Mestrado em Direito) - Programa de Pós-Graduação em Direito da Facudlade de Direito da Universidade de São Paulo, 2010. Disponível em: http://www.teses.usp.br/teses/disponiveis/2/2132/tde-01122010-134441/pt-br.php. Acesso em: 18 dez. 2018. COSTA, Isac Silveira da. High Frequency Trading (HFT) em câmera lenta: compreender para regular. 2018. Dissertação (Mestrado em Direito e Desenvolvimento) - Escola de Direito de São Paulo, Fundação Getúlio Vargas, São Paulo, 2018. 333p. Disponível em: <http://hdl.handle.net/10438/20720>. Acesso em: 18 dez. 2018. TANNOUS, Thiago Saddi. Proteção à liquidez no mercado de capitais brasileiro, cit., p. 85 .

${ }^{55}$ Vide, exemplificadamente: VEIGA, Marcelo Godke. O mercado secundário de valores mobiliários: as bolsas. Feb. 2013. 46 p. Disponível em: <https://papers.ssrn.com/sol3/papers.cfm?abstract_id=2264538>. Acesso em: $18 \mathrm{dez} .2018$.

BERTONCELLO, Fernando Rodrigues da Motta; BORGES, Letícia Menegassi. A intervenção regulatória sobre a inovação tecnológica no mercado de capitais: uma visão sob a óptica das sociedades corretoras de valores mobiliários e as operações de high frequency trading. In: CONGRESSO NACIONAL DO CONPEDI, 23., Direito e Novas Tecnologias II. Universidade Federal da Paraíba, João Pessoa, 2014. p. 220238. Disponível em: $<$ http://www.publicadireito.com.br/artigos/?cod=0c6de67934d41319>. Acesso em: 07 jan. 2017.
} 
O trabalho se divide em cinco capítulos. O primeiro apresenta o HFT ao leitor, relatando o seu surgimento e desenvolvimento, realçando características importantes, eventos, esforços regulatórios, de forma a permitir uma visão sobre a inserção do tema no mercado global.

No segundo capítulo, pontuam-se alguns aspectos essenciais do HFT para os fins do presente trabalho. Nele, empreende-se uma análise das feições que o HFT assume como produto da inovação tecnológica - e que causam repercussões para o mercado de valores mobiliários.

O terceiro capítulo examina o aparato organizado em função das operações com HFT no Brasil. Examina, para tanto, elementos de microestrutura de mercado (de forma específica, as instituições e relações) e a infraestrutura tecnológica de bolsa no país (suportes, mecanismos, sistemas, processos, meios de comunicação, dentre outros fatores).

Observado e bem delimitado o objeto de nosso estudo, permite-se, então uma aproximação da figura (e de seus problemas) com a ciência jurídica. Assim, o quarto capítulo expõe e avalia o alcance do quadro regulatório vigente. $\mathrm{O}$ arcabouço atual contempla a questão do tratamento dos riscos dessa nova forma de operar trazida pelo HFT? Erige uma estrutura de mercao de valores mobiliários justa, ordenada e confiável?

Por fim, o quinto capítulo, aborda como a 'caixa de ferramentas' regulatória do mercado de valores mobiliários precisa se adaptar. Sugerem-se, então, algumas escolhas possíveis para endereçar o objetivo de formular uma regulação prudencial voltada a promover a integridade do mercado. 


\section{CONCLUSÃO}

O exagero que permeou as discussões iniciais sobre o HFT, até o momento, não se concretizou na forma de crises disseminadas, de grandes impactos para o mercado como um todo, de catástrofes financeiras. No Brasil, as respostas regulatórias mais urgentes de que se tem notícia tem tratado de algumas situações de condutas irregulares pontuais.

Ainda assim, o HFT requer tratamento e atenção. A representatividade desta forma de negociação no mercado tem sido a força motriz para uma série de transformações de relevo no mercado de bolsa brasileiro. Liste-se, por exemplo, a mudança no papel do intermediário; a criação de ferramentas de controles de riscos disponibilizadas tanto para o intermediário quanto para o investidor; a oferta de produtos e serviços pela entidade administradora voltados especificamente para traders de alta frequência; uma intensa atividade normativa; assim como a concessão de benefícios na forma de cobrança de taxas diferenciadas para esse público investidor.

Ao invés do glamour do emprego de tecnologias desconhecidas para a obtenção de vantagens por uns investidores sobre outros, o estudo do HFT exige hoje, na verdade, que se examine como os players envolvidos no cotidiano das negociações em bolsa estruturam e organizam as respectivas 'casas', tendo por objetivo edificações resistentes, assim como a forma como estabelecem 'caminhos' e 'portas' para interagir entre si.

O HFT, a princípio, é apenas isso: um meio de se concretizar um negócio típico.

Ocorre que esse meio, que é tão real e material quanto o telégrafo, a boleta e a lousa é proveniente de um substrato diverso: ele pertence ao domínio das coisas virtuais. Ele reage autonomamente a informações. O tempo de sua ação se descola daquele da capacidade humana. Ele não tem pretensões de perenidade; pelo contrário, está em constante aprimoramento. Além disso, ele tem um escopo: está ao dispor da evolução, o que acontece com mais facilidade quando diversos indivíduos colaboram para sua melhoria, em favor da coletividade.

As formas de regular o HFT até o momento não têm levado em consideração essa natureza. Várias são as consequências disto. A criação de regras

(i) não acompanha as mutações do HFT;

(ii) é deficiente desde o início, porque busca regrar algo que é incerto; 
(iii) deixa de envolver em seu desenvolvimento os sujeitos impactados, aqueles que teriam a qualificação técnica e o interesse para melhor pensar a ferramenta;

(iv) impõe atribuições que sobrecarregam alguns indivíduos, na medida em que não viabiliza o compartilhamento de atribuições e responsabilidades que, por natureza, precisam ser compartilhadas.

Disso não resulta que a atividade normativa do regulador e do autorregulador está fadada à extinção. A proposta de transparência do modelo algorítmico no capítulo 5 acima foi inserida na ordenação jurídica europeia mediante norma. Nada impede, contudo que, em sede de convênio entre regulador, entidade administradora de mercado de bolsa e um centro de pesquisa em tecnologia de uma universidade se desenvolva uma plataforma para que os HFT-sujeitos insiram informações suficientes para que regulador, autorregulador e intermediário façam o controle em tempo real do HFT-algoritmo.

A mudança de paradigma também não significa ausência de controle ou desregulamentação. Trata-se de efetivamente regular o que é passível de ser regulado, de forma adequada com sua natureza. Vide o exemplo da regulação automatizada examinada acima a partir da ideia de Lessig: a ferramenta contém a própria lei, não porque uma regra assim determinou ou porque um contrato assim contempla, mas porque o código que dá existência ao objeto está permeado por instruções.

A colaboração que se verifica no desenvolvimento da atividade inventiva tem ainda um outro benefício: entraves relacionados a recursos materiais e humanos escassos podem mitigados pela repartição dos custos.

Embora a maior parte dos estudos enderece a questão da qualidade e eficiência de mercado, a questão das estruturas e da organização do HFT deve anteceder tais discussões. É matéria de regulação prudencial, que entendemos necessitar de atenção urgente em nosso ordenamento jurídico de forma a aproveitar a oportunidade que a inovação tecnológica dá aos países em busca do desenvolvimento.

Uma série de desdobramentos para investigações posteriores em continuidade a esse trabalho podem ser facilmente visualizados. Para os intermediários, que estão enfrentando uma readequação de seus papeis tradicionais, uma 'corrida armamentista' pode significar a concentração em poucas instituições com maiores recursos. Para a bolsa, o eminente surgimento de uma concorrente tende a trazer toda a sorte de dificuldades de consolidação de informações, de necessidade padronização de dados e informações para fins de 
supervisão, sem contar com a possibilidade de também se estabelecer uma concorrência tecnológica. Em um cenário em que sequer se sabe ainda as repercussões da ferramenta para a única instituição existente e em que o mercado de valores mobiliários ainda está em desenvolvimento em termos de atração da poupança popular, é necessário ponderar o que a entrada de um novo participante poderia adicionar em termos de instabilidade ao mercado.

De forma ainda mais premente, há que se investigar qual a interface entre as empresas de base tecnológica que se valem da alcunha de fintechs com as operações em alta frequência. Se a pouca regulação sobre a atividade do investidor usuário do HFT com conexão direta patrocinada já causa preocupação para o direito do mercado de valores mobiliários nacional, mesmo contando com o intermediário como gatekeeper, a atuação de um agente sem qualquer regulação e sobre o qual pouco se sabe, requer um acompanhamento próximo. 


\section{REFERÊNCIAS}

ABROL, Samir; CHESIR, Benjamin; MEHTA, Nikhil. High Frequency Trading and US stock market microstructure: a study of interactions between complexities, risks and strategies residing in U.S. Equity market microstructure. Financial Markets, Institutions \& Instruments, [S.1.], v. 25, n. 2, p. 107-165, May 2016. Disponível em: $<$ https://papers.ssrn.com/sol3/papers.cfm?abstract_id=2768460\#\#>. Acesso em: $21 \mathrm{dez}$. 2018.

ADLER, Adam. High frequency regulation: a new model for market monitoring. Vermont Law Review, Vermont, v. 39, n. 161, p. 162-205, 2014. Disponível em: $<$ https://lawreview.vermontlaw.edu/wp-content/uploads/2011/09/39-08_Adler.pdf $>$.

Acesso em: 19 dez. 2018.

ALDRIDGE, Irene. High-frequency trading: a practical guide to algorithmic strategies and trading systems. 2. ed. Hoboken: Wiley, 2013. 306 p.

ALMEIDA, Miguel Santos. Introdução à negociação de alta frequência. Cadernos do Mercado de Valores Mobiliários, n. 54, p. 23-36, ago. 2016. Disponível em: $<$ http://www.cmvm.pt/pt/EstatisticasEstudosEPublicacoes/CadernosDoMercadoDeValores Mobiliarios/Documents/Cadernos\%20MVM\%2054.pdf>. Acesso em: 19 dez. 2018.

ALVAREZ, Luciana. Robôs podem ler processos e até escrever petições. Estadão, 14 ago. 2018. Disponível em: <https://educacao.estadao.com.br/noticias/geral,robos-podem-lerprocessos-e-ate-escrever-peticoes, 70002449375>. Acesso em: 01 dez. 2018.

ANBIMA - ASSOCIAÇÃO BRASILEIRA DAS ENTIDADES DOS MERCADOS FINANCEIRO E DE CAPITAIS. Alemanha dá o primeiro passo na regulação do highfrequency trading. 2013. Disponível em: $<$ http://www.anbima.com.br/en_us/informar/regulacao/internacional/radar/alemanha-da-oprimeiro-passo-na-regulacao-do-high-frequency-trading.htm>. Acesso em: $21 \mathrm{dez} .2018$.

ANGEL, James. When finance meets physics: the impact of the speed of light on financial markets and their regulation. The Financial Review, v. 49, n. 2, p. 1-15, May 2014. Disponível em: <https://papers.ssrn.com/sol3/papers.cfm?abstract_id=2378352>. Acesso em: 19 dez. 2018.

AQUILINA, Matteo; YSUSI, Carla. Are high-frequency traders anticipating the order flow? Cross-venue evidence from the UK market. FCA occasional papers in financial regulation. Occasional Paper, n. 16, p. 1-39, abr. 2016. Disponível em: $<$ https://www.fca.org.uk/publication/occasional-papers/occasional-paper-16.pdf $>$. Acesso em: 21 dez. 2018.

ARAÚJO, Alcides Carlos de. Combinações de projeções de volatilidade baseadas em medidas de risco para dados em alta frequência. Tese (Doutorado). Faculdade de Economia, Administração e Contabilidade. Programa de Pós-Graduação em Administração. USP. São Paulo, 2016. Disponível em: <http://www.teses.usp.br/teses/disponiveis/12/12139/tde11072016-153404/en.php>. Acesso em: 18 dez. 2018. 
ASQUINI, Alberto. Profili dell'impresa. Rivista Commerciale, 1943, v. 41, L; COMPARATO, Fábio Konder. Perfis da Empresa. Revista de Direito Mercantil, Industrial, Econômico e Financeiro, São Paulo, n. 104, p. 109-126, out. 1996.

B3 BRASIL, Bolsa e Balcão. Disponível em: <http://ri.bmfbovespa.com.br/>. Acesso em: 01 dez. 2018.

Line Trading - Manual Conceitual. Disponível em:

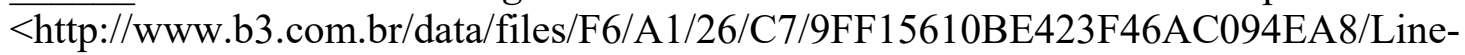
Trading-Manual-Conceitual-1.6.pdf > . Acesso em: 07 jan. 2019.

. Manual de Procedimentos Operacionais de Negociação da B3. 2018. Disponível em: $<$ http://www.b3.com.br/pt_br/regulacao/estrutura-normativa/operacoes/>. Acesso em: 21 dez. 2018.

Oficio Circular 050/2018-VOP. 2018. Disponível em: $<$ http://www.b3.com.br/data/files/87/55/31/C3/698C7610F157B776AC094EA8/OC\%2005 0-2018-VOP $\% 20$ Consulta $\% 20 \mathrm{P} \% \mathrm{C} 3 \%$ BAblica $\% 20$ Facilitation.pdf $>$. Acesso em: $31 \mathrm{dez}$. 2018.

Oficio Circular 063/2017-DP. 2017. Disponível em:

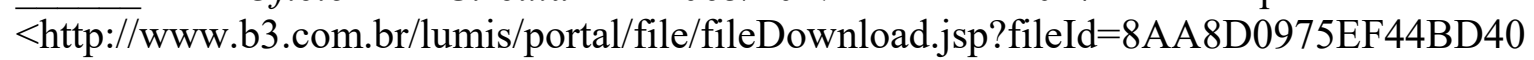
15F02E8919D1EC6>. Acesso em: 31 dez. 2018.

. Oficio Circular 071/2017-DP, 08 de novembro de 2017. Disponível em: $\overline{<\mathrm{http}: / / \text { www.b3.com.br>. }}$

Política Comercial do Co-location. 2018. Disponível em: $\overline{<\mathrm{http}: / / w w w . b 3 . c o m . b r / d a t a / f i l e s / 11 / 66 / C A / E 9 / 073 E 6610 E 634 F D 66 A C 094 E A 8 / P o l i t i c a-~}$ Comercial-do-Co-location_2.0.pdf>. Acesso em: $31 \mathrm{dez} .2018$.

. Programa de Qualificação Operacional: roteiro básico, 2019. Disponível em: <http://www.b3.com.br/data/files/40/43/D7/46/38DA3610DF40D936790D8AA8/Novo\%2 0Roteiro\%20Basico\%20-\%20JAN\%202019.pdf>. Acesso em: 31 dez. 2018.

Regulamento de Negociação da B3. 2018. Disponível em: $\overline{<\mathrm{http}: / / w w w . b 3 . c o m . b r / d a t a / f i l e s / 82 / 66 / 1 B / 34 / E 1 B 1661044682166 A C 094 E A 8 / R e g u l a m e ~}$ nto $\% 20 \mathrm{de} \% 20$ Negociacao\%2004\%2009\%202018\%20-\%20CVM.pdf $>$. Acesso em: 18 out. 2018.

. Roteiro Básico: conformidade com as regras do mercado, 2019. Disponível em:

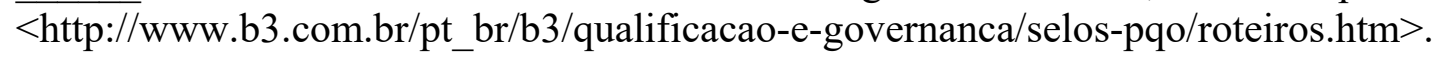
Acesso em: 07 jan. 2019.

BACEN - BANCO CENTRAL DO BRASIL. Regulação Prudencial. 2017. Disponível em: $<$ https://www.bcb.gov.br/acessoinformacao/legado?url=https:\%2F\%2Fwww.bcb.gov.br\%2 Fnor\%2Fbasileia\%2Fperguntas.asp\%3Fidpai\%3Dregprudencial>. Acesso em: 07 jan. 2019. 
BAINBRIDGE, Stephen M. Dodd-Frank: Quack Federal Corporate Governance Round II. UCLA School of Law, Law-Econ Research Paper, Los Angeles, n. 10-12, p. 1-43, Sept. 2010. Disponível em: <https://papers.ssrn.com/sol3/papers.cfm?abstract_id=1673575>. Acesso em: 18 dez. 2018.

BARNES, Rosemary. Renaissance Technologies aims at HFT by using Atomic Clock: renaissance technologies has applied for a patent for an invention designed to beat high speed traders. 2016. Disponível em: <https:/www.financemagnates.com/institutionalforex/execution/renaissance-technologies-aims-hft-using-atomic-clock/>. Acesso em: 20 dez. 2018.

BATOG, Christina. Blockchain: A Proposal to reform high frequency trading regulation. Cardozo Arts \& Ent. L.J.. v. 33, p. 755, 2015.

BERCOVICI, Gilberto. Ciência e inovação sob a Constituição de 1988. Revista dos Tribunais, São Paulo, v. 101, n. 916, p. 267-295, fev. 2012.

BERTONCELlO, Fernando Rodrigues da Motta; BORGES, Letícia Menegassi. A intervenção regulatória sobre a inovação tecnológica no mercado de capitais: uma visão sob a óptica das sociedades corretoras de valores mobiliários e as operações de high frequency trading. In: CONGRESSO NACIONAL DO CONPEDI, 23., Direito e Novas Tecnologias II. Universidade Federal da Paraíba, João Pessoa, 2014. p. 220-238. Disponível em: <http://www.publicadireito.com.br/artigos/?cod=0c6de67934d41319>. Acesso em: 07 jan. 2017.

BIAIS, Bruno; FOUCAULT, Thierry. HFT and Market Quality. Bankers, Markets \& Investors, Paris, n. 128, p. 5-19, Jan. 2014. Disponível em: <http://www.revuebanque.fr/medias/content/users/christine/1389193141609.pdf>. Acesso em: 21 dez. 2018.

BIJKERK, Werner. Market developments: high frequency trading. In: FINANCIAL STABILITY INSTITUTE/IOSCO TRAINING, 2011, Madrid, 2011. Disponível em: $<$ https://www.iosco.org/research/pdf/Market_Developments_High_Frequency_Trading.pdf $>$. Acesso em: 21 dez. 2018.

BIS - BANK FOR INTERNATIONAL SETTLEMENTS. Committee on the Global Financial System. The implications of electronic trading in financial markets. Jan. 2001. Disponível em: <https://www.bis.org/publ/cgfs16.pdf>. Acesso em: 17 dez. 2018.

Glossary: high-frequency trading (HFT). 2016. Disponível em:

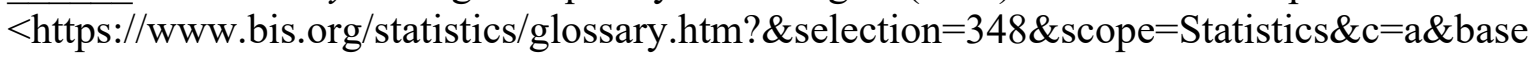
$=$ term $>$. Acesso em: 21 dez. 2018.

BM\&FBOVESPA. Manual de Acesso à Infraestrutura Tecnológica da BM\&FBOVESPA. 5.3. $2017 . \quad$ versão, Disponível em: $<$ http://www.b3.com.br/data/files/9A/17/33/2C/7FF846109988C646AC094EA8/ManualAcesso-Infraestrutura-Tecnologica-BMFBOVESPA.pdf>. Acesso em: 19 dez. 2018.

Manual de Acesso da BM\&FBovespa. 2017. Disponível em: <http://www.b3.com.br/data/files/89/00/1B/8A/286BB510CAF42BB5790D8AA8/Manual $\% 20 \mathrm{de} \% 20$ Acesso.pdf $>$. Acesso em: $31 \mathrm{dez} .2018$. 
BM\&FBOVESPA. Ofício Circular 028/2010-DP. 2010. Disponível em: $<$ http://www.bmf.com.br/bmfbovespa/pages/boletim1/informes/2010/agosto/OC028-2010DP.pdf $>$.

Oficio Circular 030/2010-DP, 09 de agosto de 2010. Disponível em:

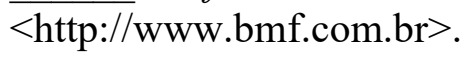

Ofício Circular 067/2012-DP. 2012. Disponível em: $<$ http://www.bmfbovespa.com.br/lumis/portal/file/fileDownload.jsp?fileId=8AA8D09752 AE99370152B1071A06717A>. Acesso em: 31 dez. 2018.

- Regulamento de Acesso da BM\&FBovespa. Ago. 2017. Disponível em: $<$ http:/www.b3.com.br/data/files/CF/E6/60/81/0BF606107D0F9606790D8AA8/Regulame nto-de-Acesso-20180828.pdf>. Acesso em: 31 dez. 2018.

BOGLE, John. No speed limits: high frequency trading and flash boys. Journal of Portfolio Management, Summer 2014.

BONALDI, Eduardo Vilar. O pequeno investidor na bolsa de valores: uma análise da ação e da cognição econômica. 2010. Dissertação (Mestrado) - Departamento de Sociologia. Faculdade de Filosofia, Letras e Ciências Humanas, USP. 2010.

BORCH, Christian; LANGE, Ann-Christina Lange. High-frequency trader subjectivity: emotional attachment and discipline in an era of algorithms. Socio-Economic Review, v. 15, n. 2, p. 283-306, 2017.

BRANUM, Samuel. SEC to increase oversight of high frequency trading firms under a proposed amendment to Rule 15b9-1. 2017. Disponível em: $<$ http://illinoisjltp.com/timelytech/sec-to-increase-oversight-of-high-frequency-tradingfirms-under-a-proposed-amendment-to-rule-15b9-1/>. Acesso em: 21 dez. 2018.

BRASIL. Lei $n$. 9.609, de 19 de fevereiro de 1998. Dispõe sobre a proteção da propriedade intelectual de programa de computador, sua comercialização no País, e dá outras providências. Disponível em: <http://www.planalto.gov.br/ccivil_03/leis/19609.htm>. Acesso em: 21 out. 2018.

BROGAARD, Jonathan et al. Trading Fast and Slow: Colocation and Liquidity. Review of Financial Studies, p. 1-63, Aug. 2015. Disponível em: $<$ https://papers.ssrn.com/sol3/papers.cfm?abstract_id=2317797>. Acesso em: 19 dez. 2018.

BRUMMER, Chris. Disruptive technology and securities regulation. Fordham Law Review, v. 84, n. 3, p. 977-1052, 2015. Disponível em: $<$ http://ir.lawnet.fordham.edu/flr/vol84/iss3/6>. Acesso em: 04 nov. 2018.

BSM - BM\&FBovespa. Caso 4: Spoofing (geração de condições artificiais de demanda). Disponível em: <http://www.bsm-autorregulacao.com.br/supervisao-de-mercado/casos/4>. Acesso em: 21 nov. 2018. 
BUDISH, Eric; CRAMTON, Peter; SHIM, John. The high-frequency trading arms race: frequent batch auctions as a market design response. The Quarterly Journal of Economics, v. 130, n. 4, p. 1547-1621, Nov. 2015. Disponível em: $<$ https://academic.oup.com/qje/article/130/4/1547/1916146>. Acesso em: 20 dez. 2018.

; ___ _ . The high-frequency trading arms race: frequent batch auctions as a market design response. Meeting of the CFTC Technology Advisory Committee, Feb. $10^{\text {th }}$, $2014 . \quad$ Disponível em: $<$ https://www.cftc.gov/sites/default/files/idc/groups/public/@newsroom/documents/file/tac 021014_budish.pdf $>$.

BUNGE, Jacob. SEC: knight capital missed warnings before errant trades: firm charged with multiple violations and given $\$ 12$ million penalty. 2013. Disponível em: $<$ https://www.wsj.com/articles/sec-levies-12-million-penalty-over-errant-knight-capitaltrades-1381940340>. Acesso em: 19 dez. 2018.

BUSCH, Danny. MiFID II: Regulating high frequency trading, other forms of algorithmic trading and direct electronic market access. Law and Financial Markets Review, v. 10, n. 2 , p. 72-82, July 2016. Disponível em: $<$ https://www.tandfonline.com/doi/full/10.1080/17521440.2016.1200333>. Acesso em: 19 dez. 2018.

CALABRÓ, Luiz Felipe Amaral. Regulação e autorregulação: teoria palco-plateia. 1. ed. São Paulo: Almedina Brasil, 2011.

CARRASCOSA LÓPEZ, V.; POZO ARRANZ, Mª A.; RODRÍGUEZ DE CASTRO, E. P. La contratación informática: el nuevo horizonte contractual: los contratos electrónicos e informáticos. 3. ed. Granada: Comares, 2000.

CARRION, Bruna Maia. BM\&FBOVESPA exibe data center e manda recado para concorrentes. Capital Aberto, 18 mar. 2014.

CASTELLS, Manuel. A sociedade em rede. 11 ed. São Paulo: Paz e Terra, 2008 (A era da Informação: Economia, Sociedade e Cultura. v. 1).

CHAPMAN, John. Don't slap a new tax on high-frequency trading. 2016. Disponível em: $<$ https://mises.org/wire/dont-slap-new-tax-high-frequency-trading $>$. Acesso em: $18 \mathrm{dez}$. 2018.

CHOI, Stephen J. Regulating investors not issuers: a market-based proposal. California Law Review, 2000. Disponível em: <https://ssrn.com/abstract=202049>.

CHRISTENSEN, Clayton M.; RAYNOR, Michael E.; MCDONALD, Rory. What Is Disruptive Innovation? Harvard Business Review. December 2015. Disponível em: $<$ https://hbr.org/2015/12/what-is-disruptive-innovation>. Acesso em: $01 \mathrm{dez} .2018$.

CLARK, Carol. How to keep markets safe in the era of high-speed trading. Chicago Fed Letter, The Federal Reserve Bank of Chicago, n. 303, p. 1-4, out. 2012. Disponível em: $<$ https://www.chicagofed.org/ /media/publications/chicago-fedletter/2012/cfloctober2012-303-pdf.pdf>. Acesso em: 17 dez. 2018. 
CLINCH, Matt. Italy launches tax on high-frequency transactions. 2013. Disponível em: $<$ https://www.cnbc.com/id/101002422>. Acesso em: 19 dez. 2018.

COFFEE, JR., John C.. Understanding Enron: It's about the Gatekeepers, Stupid. The Business Lawyer, v. 57, Aug. 2002, p. 1405.

COLLINS, Daniel P. High frequency traders: fall guys or felons? Futures Magazine: market structure, p. 14-17, May 2014. Disponível em: $<$ http://www.futuresmag.com/2014/05/01/high-frequency-traders-fall-guys-or-felons $>$. Acesso em: 17 dez. 2018.

COLLUSSI, Pedro Barguil. PEREIRA, Pedro L. Valls. The brazilian foreign exchange market through the microstructure perspective. Working Paper, 396, CEQEF n. 23, jul. 2015.

COMMISSION DE L'ÉTHIQUE EN SCIENCE ET EN TECHNOLOGIE. Gouvernement du Québec. Ethical issues of high-frequency trading: summary and recommendations. 2016. Disponível em: <http://www.ethique.gouv.qc.ca/en/assets/documents/THF/CESTTHF_EN\%20vf_A.pdf>. Acesso em: 19 dez. 2018.

COMO escolher o robô investidor ideal para o seu perfil? Infomoney, 24 jul. 2018. Disponível em: $\quad<$ https://www.infomoney.com.br/conteudopatrocinado/noticia/7532314/como-escolher-robo-investidor-ideal-para-seu-perfil $>$.

CORMEN, Thomas; LEISERSON, Charles E.; RIVEST, Ronald L., STEIN, Clifford. Introduction to algorithms. 3. ed. Elsevier, 2009.

COSTA, Isac Silveira da. High Frequency Trading (HFT) em câmera lenta: compreender para regular. 2018. 333 p. Dissertação (Mestrado em Direito e Desenvolvimento) - Escola de Direito de São Paulo, Fundação Getúlio Vargas, São Paulo. Disponível em: $<$ http://hdl.handle.net/10438/20720>. Acesso em: 18 dez. 2018.

CUSTÓDIO, Sueli Sampaio Damin. Política e teoria monetária em Nicole Oresme. In: CARVALHO, Marcelo; ÉVORA, Fátima R.; TOSSATO, Claudemir Roque; PESSOA JR., Oswaldo (Orgs.). Filosofia da ciência e da natureza. 26. ed. São Paulo: ANPOF, 2015. p. 53-70. (Coleção XVI Encontro ANPOF). Disponível em: $<$ http://www.anpof.org/portal/images/Colecao_XVI_Encontro_ANPOF/Filosofia_da_cinci a_e_da_natureza.pdf $>$. Acesso em: $17 \mathrm{dez} .2018$.

CVM - COMISSÃO DE VALORES MOBILIÁRIOS. Edital de Audiência Pública SDM N ${ }^{o}$ 04/09. Rio de Janeiro, 26 nov. 2018. Disponível em: $<$ http://www.cvm.gov.br/export/sites/cvm/audiencias_publicas/ap_sdm/anexos/2018/sdm0 418edital.pdf $>$.

. Edital de Audiência Pública. SDM N 05/18. Rio de Janeiro, 8 out. 2018. Disponível em:

$<$ http://www.cvm.gov.br/export/sites/cvm/audiencias_publicas/ap_sdm/anexos/2018/sdm0 518Edital_com_minuta.pdf $>$. 
CVM - COMISSÃO DE VALORES MOBILIÁRIOS. Instrução CVM n. 505, de 27 set. 2011. Rio de Janeiro, 2011. p. 1-19. Estabelece normas e procedimentos a serem observados nas operações realizadas com valores mobiliários em mercados regulamentados de valores mobiliários. Disponível em: <http://www.cvm.gov.br/legislacao/instrucoes/inst505.html>. Acesso em: 21 dez. 2018.

. Instrução CVM No 539, de 13 de novembro de 2013, com as alterações introduzidas pelas Instruções CVM No 554/14, 593/17 e 604/18. Disponível em: $<$ http://www.cvm.gov.br/legislacao/instrucoes/inst539.html $>$. Acesso em: 21 dez. 2018.

Instrução CVM No 558, de 26 de março de 2015 com as alterações introduzidas pelas Instruções CVM $N^{o}$ 593/17, 597/18 e 604/18. Disponível em: $<$ http://www.cvm.gov.br/legislacao/instrucoes/inst558.html>. Acesso em: 21 dez. 2018.

2014.

. Mercado de valores mobiliários. Rio de Janeiro: Comissão de Valores Mobiliários,

Relatório Anual. Rio de Janeiro, 2013. Disponível em:

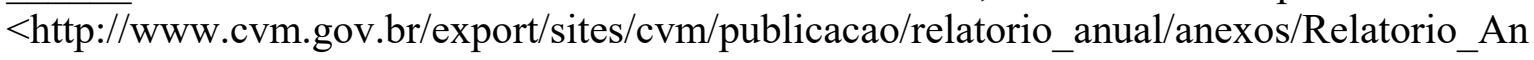
ual_2013.pdf $>$. Acesso em: 19 dez. 2018.

Relatório Anual. Rio de Janeiro, 2014. Disponível em:

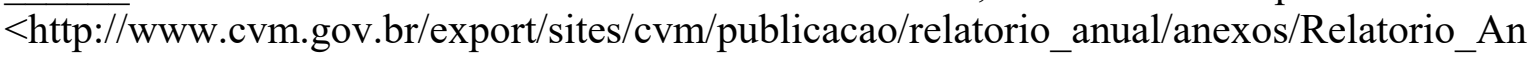
ual_2014.pdf $>$. Acesso em: 19 dez. 2018.

.. Supervisão Baseada em Risco: relatório semestral, julho-dezembro, 2017. Aprovado pelo Comitê de Gestão de Riscos em 16/04/2018. Rio de Janeiro, 2017. Disponível em: $<$ http://www.cvm.gov.br/export/sites/cvm/menu/acesso_informacao/planos/sbr/Relatorio_ Semestral_julhodezembro_2017.pdf $>$.

.. Texto Integral da Instrução CVM $N^{o} 505$, de 27 de setembro de 2011 com a

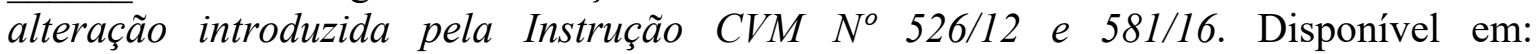
$<$ http://www.cvm.gov.br/legislacao/instrucoes/inst505.html $>$. Acesso em: 21 dez. 2018.

. Texto Integral da Instrução CVM $N^{\circ} 301$, de 16 de abril de 1999, com alterações introduzidas pelas instruções CVM $N^{o} 463 / 08$, 506/11, 523/12, 534/13 e 553/14. Disponível em: <http://www.cvm.gov.br/legislacao/instrucoes/inst301.html>. Acesso em: 21 dez. 2018.

. Texto Integral da Instrução CVM $N^{\circ} 461$, de 23 de outubro de 2007, com as alterações introduzidas pelas Instruções CVM No 468/08, 499/11, 508/11, 544/13, 554/14 e 590/17. Disciplina os mercados regulamentados de valores mobiliários e dispõe sobre a constituição, organização, funcionamento e extinção das bolsas de valores, bolsas de mercadorias e futuros e mercados de balcão organizado. Disponível em: $<$ http://www.cvm.gov.br/legislacao/instrucoes/inst461.html $>$. Acesso em: 21 dez. 2018.

Texto Integral da Instrução CVM No 168, de 23 de dezembro de 1991, com as alterações introduzidas pela Instrução CVM $N^{o}$ 252/96. Disponível em: $<$ http://www.cvm.gov.br/legislacao/instrucoes/inst168.html>. Acesso em: 21 dez. 2018. 
CVM - COMISSÃO DE VALORES MOBILIÁRIOS. Texto integral da Instrução $C V M N^{\circ}$ 380, de 23 de dezembro de 2002, com as alterações introduzidas pela Instrução 545/14. Disponível em: <http://www.cvm.gov.br/legislacao/instrucoes/inst380.html>. Acesso em: 21 dez. 2018.

DOMBALAGIAN, Onnig H. Preserving human agency in automated compliance. Brooklyn Journal of Corporate, Financial \& Commercial Law, v. 11, Aug. 2016. Disponível em: $<$ https://ssrn.com/abstract=2831611>. Acesso em: 11 out. 2018.

DONALD, David C. 'Market quality' and moral hazard in financial market design. Hong Kong, Aug. 2014. Disponível em: $<$ https://papers.ssrn.com/sol3/papers.cfm?abstract_id=2483026>. Acesso em: 21 dez. 2018.

DULLIUS, Adriana Cristina. Responsabilidade do administrador em face do artigo 245 da Lei das Sociedades Anônimas. 2017. Dissertação (mestrado) - Programa de Pós-Graduação em Direito da Faculdade de Direito da Universidade de São Pualo, São Paulo, 2017.

EIZIRIK, Nelson. Questões de direito societário e mercado de capitais. Rio de Janeiro: Forense, 1987.

; GAAL, Ariádna B.; PARENTE, Flávia; HENRIQUES, Marcus de. Mercado de capitais: regime jurídico. 3.ed. rev. e ampl. Rio de Janeiro: Renovar, 2011.

ESMA - EUROPEAN SECURITIES AND MARKETS AUTHORITY. Economic Report: high-frequency trading activity in EU equity markets. Paris, n. 12014 . 31p. Disponível em: $<$ https://www.esma.europa.eu/sites/default/files/library/2015/11/esma20141__hft_activity_in_eu_equity_markets.pdf $>$. Acesso em: 21 dez. 2018.

. MIFID II. 2017. Disponível em: < https://www.esma.europa.eu/policy-rules/mifidii-and-mifir $>$. Acesso em: 27 jul. 2018.

THE EUROPEAN PARLIAMENT. THE COUNCIL OF THE EUROPEAN UNION. Directive 2014/65/EU of the European Parliament and of the Council. 15 May 2014 on markets in financial instruments and amending Directive 2002/92/EC and Directive 2011/61/EU.

. Regulation (EU) No 596/2014 of the European Parliament and of the Council. 16 Apr. 2014. 56 p. Disponível em: <https://publications.europa.eu/en/publication-detail//publication/329793ac-f1f6-11e3-8cd4-01aa75ed71a1/language-en>. Acesso em: $21 \mathrm{dez}$. 2018.

FARHI, Maryse; PRATES, Daniela Magalhães. Playing it again: new financial innovations and renewed financial fragility. 2014. p. 1-17. Disponível em: $<$ https://even3.azureedge.net/anais/53254.pdf>. Acesso em: 19 dez. 2018.

THE FEDERAL RESERVE BANK OF CHICAGO. How to keep markets safe in the era of high-speed trading. Chicago Fed Letter. Senior policy specialist Carol Clark. October 2012, n. 303. 
FINK, Michèle. Blockchains: regulating the unknown. German Law Journal. v. 19, n. 4, 2018. Disponível em: <www.germanlawjournal.com/s/01-Vol_19_No_4_Finck.pdf >. Acesso em: 11 out. 2018.

FINRA. Distributed ledger technology: implications of blockchain for the securities industry. Jan. $2017 . \quad$ Disponível em: $<$ https://www.finra.org/sites/default/files/FINRA_Blockchain_Report.pdf $>$. Acesso em: 07 out. 2018.

FLECKNER, Andreas Martin. Regulating trading practices. The Oxford Handbook of Financial Regulation, Oxford, p. 596-630, Dec. 2015. Disponível em: $<$ https://papers.ssrn.com/sol3/papers.cfm?abstract_id=2476950>. Acesso em: 17 dez. 2018.

FOUCAULT, Thierry. Where are the risks in high frequency trading? Financial stability in the digital era. Banque de France. Financial Stability Review, n. 20, p. 59-64, Apr. 2016.

FOX, Merritt B.; GLOSTEN, Lawrence R.; RAUTERBERG, Gabriel V. The new stock market: sense and nonsense. Duke Law Journal, v. 65, n. 2, p. 191-277, Nov. 2015. Disponível em: <https://papers.ssrn.com/sol3/papers.cfm?abstract_id=2580002>. Acesso em: 17 dez. 2018.

FRANCIONI, R., GOMBER, P. High frequency trading: market structure matters. In: FRANCIONI, R., SCHWARTZ, R. (Eds). Equity markets in transition. Springer, Cham, 2017.

GERIG, Austin. High-frequency trading synchronizes prices in financial markets. 2015. 28 p. Disponível em: <https://papers.ssrn.com/sol3/papers.cfm?abstract_id=2173247>. Acesso em: 21 dez. 2018.

GILSON, Ronald J.; KRAAKMAN, Reinier H. The Mechanisms of Market Efficiency. 70 Virginia Law Review No. 70, May 1984, p. 620)

GOMBER, Peter et al. High-frequency trading. 2011. 86p. Disponível em: $<$ https://papers.ssrn.com/sol3/papers.cfm?abstract_id=1858626>. Acesso em: 20 dez. 2018.

GRAU, Eros Roberto. A Ordem Econômica na Constituição de 1988 (interpretação e crítica). 14. ed. rev. e atual. São Paulo: Malheiros Ed., 2010.

HAENSEL, Taimi. A figura dos gatekeepers. 1. ed. São Paulo: Almedina, 2014.

- A figura dos gatekeepers: aplicação às instituições intermediárias do mercado organizado de valores mobiliários brasileiro. 2014. Dissertação (Mestrado em Direito) Programa de Pós-Graduação em Direito da Faculdade de Direito da Universidade de São Paulo, São Paulo, 2014. Disponível em: $<$ http://www.teses.usp.br/teses/disponiveis/2/2132/tde-04032015-083153/en.php $>$. Acesso em: 18 dez. 2018.

HARRIS, Larry. Trading \& exchanges: market microestucture for practitioners. Oxford University Press, 2002. 
HINTON, Paul; CRAGG, Michael I. Equity market microstructure and the challenges of regulating HFT. Financier Worldwide Magazine, Jan. 2015. Disponível em: $<$ https://www.financierworldwide.com/equity-market-microstructure-and-the-challengesof-regulating-hft/\#.W4rSCOhKgdU>. Acesso em: 01 set. 2018.

HUH, Yesol. Machines vs. Machines: high frequency trading and hard information. [S.1.], 2014. $54 \quad$ p. $\quad$ Disponível em: $<$ https://papers.ssrn.com/sol3/papers.cfm?abstract_id=2341654>. Acesso em: $21 \mathrm{dez} .2018$.

IIROC. INVESTMENT INDUSTRY REGULATORY ORGANIZATION OF CANADA. Fee Model Guidelines - Update, 2018.

INFOMONEY. São Paulo, mar. 2012. Disponível em: $<$ http://www.infomoney.com.br/mercados/noticia/2376689/robos-operando-velocidadeluz-conheca-high-frequency-trading>. Acesso em: $10 \mathrm{dez} .2016$.

IOSCO - INTERNATIONAL ORGANIZATION OF SECURITIES COMMISSIONS. IOSCO Research Report on Financial Technologies (Fintech). Feb. 2017. Disponível em: $<$ https://www.iosco.org/library/pubdocs/pdf/IOSCOPD554.pdf > . Acesso em: 07 out. 2018.

. Technical Committee of the International Organization of Securities Commissions. Regulatory Issues Raised by the Impact of the Technological Changes on Market Integrity and Efficiency: Final Report. FR09/11, Oct. 2011. 85p. Disponível em: $<$ http://www.iosco.org/library/pubdocs/pdf/IOSCOPD361.pdf $>$. Acesso em: 01 jan. 2014, 02 nov. 2018.

JONES, Charles M. What do we know about high-frequency trading? Columbia Business School Research Paper, New York, n. 13-11, p. 1-56, Mar. 2013. Disponível em: $<$ https://papers.ssrn.com/sol3/papers.cfm?abstract_id=2236201\#\#>. Acesso em: $20 \mathrm{dez}$. 2018.

KIM, Kendall. Eletrocnic and algorithmic trading technology: the complete guide. 1. ed. Elsevier, 2007. 203p.

KIRILENKO, Andrei; KYLE, Albert S., SAMADI, Mehrdad; TUZUN; Tugkan. The flash crash: the impact of high frequency trading on an electronic market. version: 5. Journal of Finance, May 2014. Disponível em: <http://ssrn.com/abstract=1686004>. Acesso em: 01 out. 2014.

KORSMO, Charles. High-frequency trading: a regulatory strategy. University of Richmond Law Review, Richmond, v. 48, n. 2, p. 523-609, Feb. 2014. Disponível em: $<$ https://papers.ssrn.com/sol3/papers.cfm?abstract_id=2395915>. Acesso em: 19 dez. 2018.

KROFT, Steve. Is the stock market rigged? Mar 30 2014. Disponível em: $<$ https://perma.cc/7HEF-GXRM>. Acesso em: 01 dez. 2018.

LAUGHLIN, Gregory; AGUIRRE, Anthony; GRUNDFEST, Joseph. Information transmission between financial markets in Chicago and New York. Stanford Law and Economics Olin Working Paper, n. 442, p. 1-18, Nov. 2015. Disponível em: $<$ https://ssrn.com/abstract=2227519>. Acesso em: 20 dez. 2018. 
LESSIG, Lawrence. CODE - and other laws of cyberspace. New York: Basic Books, 2006. Code is Law - on liberty in cyberspace. Harvard Magazine, 01.01.2000. Disponível em: $<$ https://harvardmagazine.com/2000/01/code-is-law-html $>$. Acesso em: 06 out. 2018.

LEVY, Maria Bárbara. História da Bolsa de Valores do Rio de Janeiro. Rio de Janeiro, IBMEC, 1977.

LÉVY, Pierre. O que é o virtual? 2. ed. São Paulo: Ed. 34, 2011.

------. As tecnologias da inteligência: o futuro do pensamento na era da informática. 2. ed. São Paulo: Ed. 34, 2010.

LEWIS, Michael. Flash Boys: revolta em Wall Street. Rio de Janeiro: Intrínseca, 2014.

LOBOSCO, Katie. Make high-speed trading illegal: Schwab. 2014. Disponível em: $<$ https://money.cnn.com/2014/04/03/investing/schwab-high-frequency-

trading/index.html>. Acesso em: 21 dez. 2018.

LOPES, Rodrigo Soares. Aplicação de estratégias de high frequency trading no mercado brasileiro de dólar futuro. 2018. Dissertação (Mestrado em Controladoria e Contabilidade) - Faculdade de Economia, Administração e Contabilidade, Universidade de São Paulo, São Paulo. Disponível em: <http://www.teses.usp.br/teses/disponiveis/12/12136/tde-21082018142155/pt-br.php>. Acesso em: 18 dez. 2018.

. High frequency trading no mercado brasileiro. 2012. Trabalho de Conclusão de Curso (MBA em Gestão de Negócios) - IBMEC Business School, Rio de Janeiro, 2012. 64p.

MAATMAN, R.H.; TEEBOOM, P.B.; VERSCHOOR, B. High frequency trading. Ondernemingsrecht, n. 122, p. 663-671, 2012.

MACINTOSH, Jeffrey G. Hign frequency traders: angels or devils? C.D. Howe Institute Commentary, Toronto, n. 391, p. 1-29, out. 2013. Disponível em: $<$ https://papers.ssrn.com/sol3/papers.cfm?abstract_id=2340673>. Acesso em: 17 dez. 2018.

MACKENZIE, Donald. Material signals: a historical sociology of high-frequency trading. American Journal of Sociology, Chicago, v. 123, n. 6, p. 1635-1683, May 2018. Disponível em: <https://www.journals.uchicago.edu/doi/full/10.1086/697318>. Acesso em: $19 \mathrm{dez}$. 2018.

MARKETS COMMITTEE. BIS - Bank for International Settlements. High-frequency trading in the foreign exchange market. Basel, 2011. Disponível em: $<$ https://www.bis.org/publ/mktc05.pdf>. Acesso em: 21 dez. 2018.

MCNAMARA, Steven R. The Law and Ethics of High-Frequency Trading. Minnesota Journal of Law, Science \& Technology, Minneapolis, n. 71, p. 71-152, Feb. 2016. Disponível em: <https://papers.ssrn.com/sol3/papers.cfm?abstract_id=2565707>. Acesso em: $20 \mathrm{dez}$. 2018 . 
MENKVELD, Albert J. The economics of high-frequency trading: taking stock. Annual Review of Financial Economics, Amsterdã, v. 8, p. 2-28, June 2016. Disponível em: $<\mathrm{https}: / /$ ssrn.com/abstract=2787542>. Acesso em: 29 jul. 2018.

HFT good or bad?: a literature survey. June 1, 2016. Disponível em:

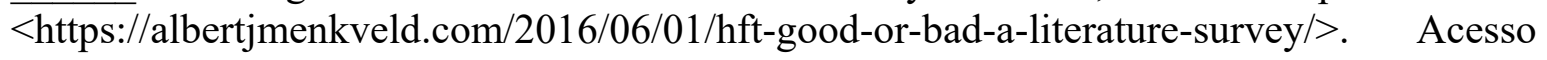
em: 17 dez. 2018.

MICHAELS, Dave; PHILIPS, Matthew; BRUSH, Silla. Slow Cop, Fast Beat: SEC takes its time on high-frequency trading rules: the SEC is taking its time studying the market before issuing rules to curb speed traders. 2014. Bloomberg Business Week. Disponível em: $<$ https://www.bloomberg.com/news/articles/2014-04-10/sec-takes-its-time-on-highfrequency-trading-rules $>$. Acesso em: 17 dez. 2018.

MILLER, Rena S.; SHORTER, Gary. High frequency trading: overview of recent developments. Congressional Research Service Reports, p. 1-19, Apr. 2014. Disponível em: $<$ https://digital.library.unt.edu/ark:/67531/metadc847719/>. Acesso em: 19 dez. 2018.

NOBESCHI, Alexandre. Saúde: como a inteligência artificial pode ajudar nos diagnósticos: empresas apostam na inteligência artificial para ajudar nos diagnósticos. $\mathrm{O}$ vazamento de dados médicos privados é o efeito colateral mais temido pelos pacientes. Época, 26 dez. 2016. Disponível em: <https://epoca.globo.com/saude/noticia/2016/12/saude-comointeligencia-artificial-pode-ajudar-nos-diagnosticos.html>. Acesso em: 17 dez. 2018.

NODA, Margareth. Acesso eletrônico e tendências para a intermediação no mercado de valores mobiliários. Dissertação (Mestrado em Direito) - Programa de Pós-Graduação em Direito da Facudlade de Direito da Universidade de São Paulo, 2010. Disponível em: http://www.teses.usp.br/teses/disponiveis/2/2132/tde-01122010-134441/pt-br.php. Acesso em: 18 dez. 2018.

NORMAN, Laurence; FROYMOVICH, Riva. EU Lawmakers Call for Enforced Delay on High-Frequency Trades. The Wall Street Journal. Sept. 26, 2012. Disponível em: $<$ https://www.wsj.com/articles/SB10000872396390443916104578020470662664506>. Acesso em: 01 dez. 2018.

NUNES, Gustavo de Faro Colen. Modelo da dinâmica de um livro de ordens para aplicações em high-frequency trading. 2013. 49 p. Dissertação (Mestrado Profissional) (Programa de Mestrado Profissional em Economia)- Fundação Getúlio Vargas/EESP, São Paulo, 2013. Disponível em: <http://hdl.handle.net/10438/10570>. Acesso em: 18 dez. 2018.

NYSE American Debuts Speed Bump. 2017. Disponível em: $<$ https://www.marketsmedia.com/nyse-american-debuts-speed-bump/>. Acesso em: $20 \mathrm{dez}$. 2018.

O'HARA, Maureen. High frequency market microstructure. Journal of Financial Economics, Rochester, v. 116, n. 2, p. 257-270, May 2015. Disponível em: $<$ https://www.sciencedirect.com/science/article/pii/S0304405X15000045>. Acesso em: 17 dez. 2018. 
ONSTAD, Eric. Lasers, microwave deployed in high-speed trading arms race. 2013. Disponível em: <https://www.reuters.com/article/us-highfrequency-microwave/lasersmicrowave-deployed-in-high-speed-trading-arms-race-idUSBRE9400L920130501>. Acesso em: 20 dez. 2018.

OPA e algoritmos de trading: CVM debate temas durante a Semana Mundial do Investidor 2017. CVM - Comissão de Valores Mobiliários, Notícias, 05 out. 2017. Disponível em: <http://www.cvm.gov.br/noticias/arquivos/2017/20171005-2.html>. Acesso em: 17 dez. 2018.

PARANÁ, Edemilson. A digitalização do mercado de capitais no Brasil: tendências recentes. 1. ed. Brasília-DF: Instituto de Pesquisa Econômica Aplicada, 2018. 44p. (Texto para Discussão 2370). Disponível em: $<$ http://repositorio.ipea.gov.br/bitstream/11058/8280/1/TD_2370.PDF $>$. Acesso em: 19 dez. 2018.

PATTERSON, Scott. High-speed stock traders turn to laser beams: anova is to use laser devices for fast communication of market data. 2014. Disponível em: $<$ https://www.fnlondon.com/articles/high-speed-stock-traders-turn-to-laser-beams20140212>. Acesso em: 20 dez. 2018.

PETER Nabicht, em entrevista a Daniel P. Collins. High Frequency Traders: fall guys or fellons? Futures Magazine. Disponível em: $<$ http://www.futuresmag.com/2014/05/01/highfrequency-traders-fall-guys-or-felons>. Acesso em: 10 out. 2014.

PINTO, Gustavo Mathias Alves. Regulação sistêmica e prudencial no setor bancário brasileiro. São Paulo: Almedina, 2015. 366 p.

PONTUSCHKA, Martin. A estratégia de pares aplicada a dados de alta frequência no mercado acionário brasileiro. 2012. 46 p. Trabalho de Conclusão de Curso de Graduação (Curso de Administração) - Escola de Administração, Universidade Federal do Rio Grande do Sul, Porto Alegre-RS, 2012. Disponível em: <http://hdl.handle.net/10183/73001>. Acesso em: 18 dez. 2018.

PROENÇA, José Marcelo Martins. Insider trading: regime jurídico do uso de informações privilegiadas no mercado de capitais. São Paulo: Quartier Latin, 2005.

RAUCHS, Michel et al. Distributed ledger technology systems: a conceptual framework. University of Cambridge, 2018.2 Disponível em: $<$ https://www.jbs.cam.ac.uk/fileadmin/user_upload/research/centres/alternativefinance/downloads/2018-08-20-conceptualising-dlt-systems.pdf $>$. Acesso em: 11 out. 2018.

ROGERS, Jonathan L.; SKINNER, Douglas J.; ZECHMAN, Sarah L. C. Run EDGAR Run: SEC Dissemination in a High-Frequency World. Chicago Booth Research Paper, Chicago, n. 14-36, p. 1-62, set. 2014. Disponível em: $<$ https://papers.ssrn.com/sol3/papers.cfm?abstract_id=2513350>. Acesso em: 21 dez. 2018.

ROMANO, Roberta. The Sarbanes-Oxley Act and the making of quack corporate Governance. Yale Law \& Economics Research Paper, New Haven, n. 297, p. 1-240, Sept. 2004. Disponível em: <https://papers.ssrn.com/sol3/papers.cfm?abstract_id=596101>. Acesso em: 18 dez. 2018. 
ROSA, Maria Eduarda Fleck da. O Poder Normativo da Comissão de Valores Mobiliários. 2012. Dissertação (Mestrado em Direito) - Programa de Pós-Graduação em Direito da Faculdade de Direito da Universidade de São Paulo, São Paulo, 2012.

SATIRO, Francisco. HAENSEL, Taimi. Direito dos valores mobiliários e do mercado de capitais. Almedina. No prelo.

SCHWAB, Charles. Schwab statement on high-frequency trading. 2014. Disponível em: $<$ https://pressroom.aboutschwab.com/press-release/corporate-and-financial-news/schwabstatement-high-frequency-trading>. Acesso em: 19 dez. 2018.

SCHWAB, Klaus. A quarta Revolução Industrial. São Paulo: Edipro, 2016.

SEC - SECURITIES AND EXCHANGE COMMISSION. 17 CFR Part 242. Concept release on equity market structure. Proposed Rule. Release No. 34-61358. Washington, D.C.: [s.n.], 2010. v. 75.

. Equity market structure in 2016 and for the future. Chair Mary Jo White. Key note address. 83rd Annual Market Structure Conference. Sept. 14, 2016. Security Traders Association. Disponível em: <https:/www.sec.gov/news/speech/white-equity-marketstructure-2016-09-14.html>. Acesso em: 27 jul. 2018.

. Securities Exchange Act of 1934 Release No. 70694 / October 16, 2013 : Administrative Proceeding File No. 3-15570, 2013. Disponível em: $<$ https://www.sec.gov/litigation/admin/2013/34-70694.pdf >. Acesso em: 19 dez. 2018.

. CFTC - Commodity Futures Trading Commission. Findings Regarding the Market Events of may 6, 2010: Report of the staffes of the CFTC and SEC to the joint advisory committee on emerging regulatory issues. 2010. Disponível em: $<$ https://www.sec.gov/news/studies/2010/marketevents-report.pdf $>$. Acesso em: 19 dez. 2018.

SILVEIRA, G. P.; SHIGUEMORI, E. H.; GOMES, V. C. F. Uso de Rede Neural Artificial para a Classificação de Vias Terrestres em Imagens Obtidas por VANTs. Revista Projetos de Engenharia, n. 2, p. 133-138, set. 2017. Disponível em: <revista.aeita.com.br/wpcontent/uploads/2017/.../Anais_VI_SCTI_2017-133-138.pdf>. Acesso em: 01 set. 2018.

STIGLITZ, Joseph E. Tapping the brakes: are less active markets safer and better for the economy? In: FINANCIAL MARKETS CONFERENCE, 2014, Atlanta. Tuning financial regulation for stability and efficiency. 2014. p. 1-14. Disponível em: $<$ http://www.reinventingbrettonwoods.org/content/tapping-brakes-are-less-active-marketssafer-and-better-economy>. Acesso em: 19 dez. 2018.

TADIELLO, Guilherme. High-frequency trading e eficiência informacional: uma análise empírica do mercado de capitais brasileiro no período de 2007-2015. Dissertação (Mestrado) - Faculdade de Economia, Administração e Contabilidade da Universidade de São Paulo, São Paulo, 2016.

TANNOUS, Thiago Saddi. Proteção à liquidez no mercado de capitais brasileiro. São Paulo, Quartier Latin, 2018. 
TIMMS, Aaron. Emerging markets look to attract high frequency traders: exchanges in Brazil, Mexico and Russia are implementing new technology and regulations in hopes of becoming hotbeds of high frequency trading. Institutional Investor-International Edition, Aug 2013. Disponível em: $<$ http://www.institutionalinvestor.com/article/3239889/Emerging-Markets-Look-toAttract-High-Frequency-Traders.html\#.VEUaG2ctDGI.>. Acesso em: 01 set. 2014.

UEMATSU, Akira Arice de Moura Galvão. Algoritmos de negociação com dados de alta frequência. 2012. Dissertação (Mestrado em Estatística) - Instituto de Matemática e Estatística, Universidade de São Paulo, São Paulo, 2012. Disponível em: $<$ http://www.teses.usp.br/teses/disponiveis/45/45133/tde-28042012-114138/pt-br.php>. Acesso em: 18 dez. 2018.

UNITED KINGDOM - UK. The future of computer trading in financial markets - an international perspective. Final Project Report. Government Office for Science. 23/10/2012. Disponível em: $<$ https://www.gov.uk/government/uploads/system/uploads/attachment_data/file/289431.

. The Government Office for Science. Foresight: the future of computer trading in financial markets. Final Project Report. London, 2012. 178p. Disponível em: $<$ https://assets.publishing.service.gov.uk/government/uploads/system/uploads/attachment_ data/file/289431/12-1086-future-of-computer-trading-in-financial-markets-report.pdf $>$. Acesso em: 18 dez. 2018.

U.S. SENATE. The role of regulation in shaping equity market structure and electronic trading: opening statement of chairman Tim Johnson. Tuesday, July 8, 2014. Committee on Banking, Housing, and Urban Affairs, Washington-DC.: Hon. Tim Johnson, Chairman of the Committee, 2014.

VEIGA, Alexandre Brandão da. Crime de manipulação, defesa e criação de mercado. Coimbra: Almedina, 2001.

VEIGA, Marcelo Godke. O mercado secundário de valores mobiliários: as bolsas. Feb. 2013. 46 p. Disponível em: $<$ https://papers.ssrn.com/sol3/papers.cfm?abstract_id=2264538>. Acesso em: 18 dez. 2018.

VIGNA, Olivier. Marchés 2014, une année charnière pour le trading à haute fréquence? Quels risques macrofinanciers pour 2014? Risques et Tendances, n. 14, 2014. Disponível em: <https://bit.ly/2RefXVW>. Acesso em: 21 dez. 2018.

VUILLEMEY, Guillaume. 4. High-Frequency Trading: A Note on Spot vs. Future Trades, Property Rights, and Settlement Risk. The Next Generation of Austrian Economics: Essays in Honor of Joseph T. Salerno. 2015. Disponivel em: https://mises.org/library/nextgeneration-austrian-economics-essays-honor-joseph-t-salerno $/ \mathrm{html} / \mathrm{p} / 537$. Acesso em: 29.07.2018.

WHATSAPP. Disponível em: <https://www.whatsapp.com/about/>. Acesso em: $01 \mathrm{dez}$. 2018. 
WELLISCH, Julya Sotto Mayor. Sistema de regulação do mercado de valores mobiliários: para além da informação. Dissertação (Mestrado) - Faculdade de Direito da Universidade de São Paulo, São Paualo, 2016.

WIENER, Jonathan B. The regulation of technology, and the technology of regulation. Technology in Society 26 (2004). p.

XP. Trader, não deixe que te enganem sobre DMA. Infomoney, 13 set. 2017. Disponível em: $<$ https://www.infomoney.com.br/conteudo-patrocinado/xpi/noticia/6946952/trader-naodeixe-que-enganem-sobre-dma>. Acesso em: 01 set. 2018.

YADAV, Yesha. The failure of liability in modern markets (Aug. 28, 2015). Virginia Law Review, n. 102, p. 1031-1100, 2016. Disponível em: $<$ https://papers.ssrn.com/sol3/Delivery.cfm/SSRN_ID2816348_code1723803.pdf?abstracti $\mathrm{d}=2652893 \&$ mirid $=1>$.

. How algorithmic trading undermines efficiency in capital markets. Vanderbilt Law Review, Nashville, v. 68, n. 1607, p. 1607-1671, 2015. Disponível em: $<$ https://papers.ssrn.com/sol3/papers.cfm?abstract_id=2400527>. Acesso em: 19 dez. 2018.

YAZBEK, Otavio. Regulação do mercado financeiro e de capitais. 2. ed. São Paulo: Elsevier; Campus, 2009. 